\title{
BARTOLOMÉ ARNOLFO, UN SABOYANO EN EL MADRID DEL SIGLO XVII, FINANCIERO, MERCADER Y SEÑOR DE GANADOS TRASHUMANTES
}

\section{Bartolomé Arnolfo, a Native from Savoy in Madrid at the Middle of the Seventeenth Century, Financier, Merchant and Owner of Transhumant Livestock}

\author{
Máximo DIAGO HERNANDO \\ Instituto de Historia, CSIC \\ Correo-e: maximo.diago@cchs.csic.es
}

RESUMEN: Madrid reunió durante el siglo XVII una nutrida comunidad de mercaderes de origen extranjero, constituida por individuos de muy diversas procedencias, que se agrupaban por naciones. Una de las naciones con menor número de miembros fue la constituida por los súbditos del duque de Saboya. En este artículo el autor analiza el perfil de uno de los miembros de esta nación, el mercader y financiero Bartolomé Arnolfo. Informa sobre su actividad mercantil, centrándose en particular en su faceta como exportador de lanas, que pone en relación con otras importantes facetas de su actividad, como el préstamo y la explotación de ganado ovino trashumante.

Palabras clave: España, Madrid, Saboya, comercio, finanzas, ganadería trashumante, siglo XVIII.

ABSTRACT: In the course of the seventeenth century a numerous community of foreign merchants took shape in Madrid. Individuals of very diverse origins conformed this community, that was divided in «nations», in which the merchants of the same origin came together. One of these «nations» was conformed by the subjects of the duke Savoy, that were not very numerous in Madrid at this time. In this article the author pays 
attention to one of the most prominent members of this nation, the merchant and businessman Bartolomé Arnolfo. He informs about his activity as a merchant, and he pays particular attention to his activity as wool exporter, that he puts in connexion with other activities such as money-lending and transhumant sheep-breeding.

Key words: Spain, Madrid, Savoy, Trade, Finance, Transhumant Sheep Breeding, Seventeenth Century.

En el transcurso del siglo xvir Madrid llegó a reunir una de las comunidades de mercaderes y financieros más numerosa y diversificada de la Corona de Castilla, a la que se incorporaron gran número de extranjeros, procedentes de los más diversos rincones de la Europa Occidental ${ }^{1}$. Su consolidación como sede permanente de la Corte, tras el regreso de Felipe III de Valladolid en 1606, fue sin duda el factor determinante que propició esta evolución. En primer lugar porque la Monarquía, con su voraz apetito de dinero, atrajo a su entorno a un gran número de financieros, los llamados asentistas, que en su inmensa mayoría fueron de origen extranjero, y desempeñaron además un destacado papel en el comercio de importación y exportación de mercancías. En segundo lugar, porque en torno a la Corte se concentraron los grupos sociales con mayor capacidad de consumo del conjunto de la población castellana, que generaron una fuerte demanda de productos, que fue satisfecha mediante su importación. De ahí que, para dar respuesta a esta demanda, gran número de mercaderes extranjeros se instalasen en la villa tras 1606 , los cuales mantenían contacto permanente con otros colegas

1. Numerosos estudios monográficos se han dedicado al estudio de determinadas comunidades de mercaderes extranjeros en particular. Cabe destacar los dedicados a los mercaderes flamencos, franceses y loreneses por RAMOS MEDiNA, M. ${ }^{a}$ D.: «Algunas sagas comerciales francesas en el Madrid de la segunda mitad del seiscientos», Espacio, Tiempo y Forma. Serie IV. Historia Moderna, 12 (1999), pp. 223-247. «El origen de una élite negociante en Madrid: Los mercaderes de lonja franceses en el siglo XVII», Espacio, Tiempo y Forma, Serie IV, Historia Moderna, 14 (2001), pp. 349-375. «Algunas compañías mercantiles francesas en el comercio minorista madrileño en la segunda mitad del seiscientos», Cuadernos de Historia Moderna, 26 (2001), pp. 57-87. «La intermediación de compañías en el comercio internacional de Madrid en el siglo XVII. El caso de las lonjas francesas (1634-1669)», Espacio, Tiempo y Forma, Serie IV, Historia Moderna, 15 (2002), pp. 65-83. Una familia de mercaderes en Madrid: los Clemente. Una historia empresarial (1639-1679). Madrid, 2000. «Mercaderes flamencos en Madrid: La Casa y Compañía DuPont (1650-1679)», Espacio, Tiempo y Forma, Serie IV, Historia Moderna, 13 (2000), pp. 221-49. Y Casas de negocios y comerciantes en el Madrid de los Austrias: 1634-1700. Universidad Nacional de Educación a Distancia, Madrid, 2004. Una visión general sobre el significado de las «naciones» en la Monarquía hispana en ÁlvarEz-Ossorio AlvARIÑO, A. y García García, B. J. (eds.): La Monarquía de las naciones: Patria, nación y naturaleza en la monarquía de España. Fundación Carlos de Amberes, Madrid, 2004. 
suyos residentes en las ciudades portuarias a través de las que entraban en Castilla gran parte de las mercancías de importación con las que se había de satisfacer la demanda madrileña, tales como Bilbao o Santander, en el Mar Cantábrico, Sevilla o Sanlúcar de Barrameda en el Atlántico, y Málaga o Alicante en el Mediterráneo.

Estos mercaderes solían agruparse por «naciones», que tuvieron durante el Antiguo Régimen un carácter muy diferente al que se les viene atribuyendo en Europa desde el siglo xIx, la centuria por excelencia de la efervescencia del «nacionalismo». Entre dichas «naciones», una de las menos conocidas es la de los súbditos del duque de Saboya. Era este un poderoso príncipe, cuyos territorios formaban parte del Imperio romano-germánico, y ocupaban una estratégica posición entre Italia, Francia y Alemania. Esto le permitió jugar un papel de primera fila en el escenario político continental, que a largo plazo hizo posible su ascenso al rango de rey a principios del siglo xviII, y que, más tarde, en torno a él se fraguase a mediados del siglo xix la unificación de Italia, a cambio de ceder a Francia la soberanía sobre parte de las tierras gobernadas por sus antepasados desde la más remota Edad Media.

Entre los súbditos del duque de Saboya hubo desde época medieval individuos dedicados al comercio a larga distancia que buscaron fortuna en la Península Ibérica. Está bien constatada su actividad en los reinos de la Corona de Aragón, pues a partir del año 1420 el rey Alfonso el Magnánimo les sometió a la obligación de abonar un nuevo impuesto por sus operaciones mercantiles de importación y exportación, conocido con el nombre de dret alemà y saboyà, pues solo estaban obligados a pagarlo los mercaderes alemanes y saboyanos ${ }^{2}$, del mismo modo que el llamado dret dels italians introducido en 1402 por el rey Martín I recaía exclusivamente sobre los mercaderes de origen italiano. De este modo los mercaderes súbditos del duque de Saboya fueron asimilados a los oriundos de las tierras del Imperio al norte de los Alpes, y diferenciados de los italianos, que también eran súbditos del Imperio. Por ello saboyanos y alemanes tuvieron a su frente en la Corona de Aragón un mismo cónsul, encargado de la defensa de sus intereses, el cual ejercía sobre todos ellos jurisdicción en determinadas materias ${ }^{3}$. Según todos los indicios, no obstante, los mercaderes súbditos del duque de Saboya desempeñaron un modesto papel en el comercio exterior de la Corona de Aragón en esta época, mucho menos relevante que el de los italianos, pero también que el de las

2. López Elum, P.: «Las relaciones comerciales de la Corona de Aragón con los alemanes y saboyanos. Dret alemà y Saboya (1420-1694)», Saitabi 26 (1976), pp. 47-57.

3. Referencias al oficio de cónsul de alemanes y saboyanos en Diago Hernando, M.: «Los mercaderes alemanes en los Reinos Hispanos durante los siglos bajomedievales: Actividad de las grandes compañías en la Corona de Aragón» en Valdeón, J., Herbers, K. y Rudolf, K. (coords.): España y el «Sacro Imperio». Procesos de cambios, influencias y acciones recíprocas en la época de la «europeización» (Siglos XI-XIII). Universidad, Valladolid, 2002, pp. 299-328. 
casas mercantiles de la Alta Alemania. Para el caso concreto de la ciudad de Valencia así lo ha destacado José Hinojosa Montalvo, quien sostiene que fueron poco numerosos durante el siglo xv y en su mayoría procedieron de Niza y Villafranca 4 .

Por lo que toca a su actividad en la Corona de Castilla durante el período bajomedieval no es mucho lo que se sabe. Así, resulta sintomático que en su panorama general sobre la presencia y actividad de mercaderes extranjeros en este reino en época de los Reyes Católicos, Bello León no haga referencia a los saboyanos como grupo diferenciado. Y en el largo elenco de mercaderes extranjeros que nos ofrece tan solo incluye cinco individuos originarios de Niza que residieron en las islas Canarias, y otro procedente de esta misma ciudad, llamado Enrique Spañol, del que se desconoce la vecindad ${ }^{5}$. Tampoco los trabajos de investigación dedicados a la Edad Moderna han aportado apenas informaciones sobre la presencia de mercaderes saboyanos en la Corona de Castilla, con la única excepción significativa de una monografía dedicada a un mercader de este origen que en las décadas finales del siglo xvi residió en la ciudad de Cádiz, el cual escribió unas memorias de notable interés para la reconstrucción de su trayectoria como mercader ${ }^{6}$.

Para colmar en parte este vacío historiográfico, hemos considerado de interés realizar una pequeña contribución al estudio del papel de los mercaderes saboyanos en el comercio exterior hispano, centrándonos en el análisis de la trayectoria de un individuo que formaba parte de esta «nación» y arraigó en Madrid a mediados del siglo xvir. Se trata de Bartolomé Arnolfo, de quien hemos logrado reunir abundante información en los protocolos notariales madrileños y otros fondos archivísticos, como el de la Inquisición, que nos ha permitido profundizar en el análisis de variados aspectos de su perfil como hombre de negocios y miembro de la sociedad madrileña de tiempos de Felipe IV. Por el contrario, dicha información ha resultado de mucha menor utilidad para conocer su perfil como miembro de la comunidad saboyana residente en la villa y Corte, pues apenas hace referencia a las relaciones por él mantenidas con otros individuos pertenecientes a esta comunidad'.

Es bastante probable que los saboyanos, por ser pocos, no llegasen a constituir una comunidad tan bien definida como las que conformaron otras «naciones» que contaron con sus iglesias y hospitales como instituciones aglutinantes. En

4. Hinojosa Montalvo, J.: «Sobre mercaderes extrapeninsulares en la Valencia del siglo XV», Saitabi, 26 (1976), pp. 59-92, en especial p. 84.

5. Bello León, J. M.: Extranjeros en Castilla (1474-1501). Universidad, La Laguna, 1994.

6. Bustos Rodríguez, M. (ed.): Un comerciante saboyano en el Cádiz de Carlos II (Las memorias de Raymundo de Lantery, 1673-1700). Caja de Ahorros, Cádiz, 1983.

7. Contemporáneos de Bartolomé Arnolfo, y residentes en Madrid, fueron, entre otros, los saboyanos Esteban Malet y su hijo Jorge, originarios de Venza, la actual Vence, en Francia. Esteban Malet pagó derechos aduaneros por mercancías introducidas en la Corona de Castilla a través de la aduana de Ágreda en 1646. Archivo Histórico Provincial de Soria, Protocolos Notariales, 1574-2367-86. 
cualquier caso el objeto del presente trabajo no es el de profundizar en el análisis del funcionamiento de la comunidad saboyana en Madrid. Nos limitaremos a reconstruir el perfil de un único individuo perteneciente a la misma a mediados del siglo xvir, el cual, por la singularidad de su trayectoria, apenas nos permite entrever nada significativo sobre el tipo de relaciones que mantenían entre sí los saboyanos entonces residentes en la villa del Manzanares. De hecho, las personas con las que nuestro protagonista mantuvo más estrechos y permanentes contactos fueron italianos y castellanos. $\mathrm{Y}$ al análisis de dichos contactos dedicaremos preferentemente nuestra atención, con el objeto de desvelar sus estrategias de integración social y de promoción en los escenarios económico y sociopolítico mediante el desempeño de una compleja y diversificada actividad mercantil y financiera. De este modo nos proponemos efectuar una pequeña contribución al análisis del régimen de funcionamiento de los mercados financieros y mercantiles en la Corona de Castilla a mediados del siglo xvir, y a la reconstrucción de los perfiles sociopolíticos de las personas que entonces desempeñaron un papel más activo en dichos mercados.

\section{Algunas pinceladas biográficas}

Bartolomé Arnolfo había nacido en la ciudad de Tenda, próxima a Niza, al pie de los Alpes Marítimos, que formaba parte de los dominios del duque de Saboya ${ }^{8}$. Nada hemos conseguido averiguar sobre su trayectoria desde su nacimiento hasta su instalación en Madrid, que debió producirse hacia fines de la década de 1620, cuando comenzamos a encontrar su nombre en los protocolos notariales madrileños, en un primer momento en la forma de Bartolomé Arnolfino. Un documento del año 1634 lo identifica como persona que estaba en casa de Juan Lucas Palavesín?, poderoso financiero genovés que efectuó numerosos préstamos a la Monarquía hispana en este período ${ }^{10}$. Y más adelante, en otros documentos, lo encontramos

8. Tomamos la noticia de Archivo Histórico de Protocolos de Madrid [en adelante AHPM], 5266-152 [indicamos siempre el número de protocolo y, seguido de guión, el del primer folio del documento]. Esta ciudad forma parte en la actualidad de Francia, donde es conocida con el nombre de Tende.

9. En 1634 Alonso García Silíceo, vecino de Badajoz, dirige una letra a Bartolomé Arnolfo «en casa de Juan Lucas Palavesin». AHPM, 5291-78.

10. Álvarez Nogal, C.: El crédito de la Monarquía hispánica en el reinado de Felipe IV. Junta de Castilla y León, Valladolid, 1997, pp. 235 y ss. y 264 y ss. Y Los banqueros de Felipe IV y los metales preciosos americanos. Banco de España, Madrid, 1997. Domínguez OrTiz, A.: Política y Hacienda de Felipe IV. Derecho Financiero, Madrid, 1960, p. 114. Y Ruiz MarTín, F.: Las finanzas de la Monarquí Hispánica en tiempos de Felipe IV, 1621-1665. Real Academia de la Historia, Madrid, 1990. Juan Lucas Palavesín es la versión castellana de Gio Luca Pallavicino, su nombre en italiano. 
calificado explícitamente como oficial mayor de sus libros ${ }^{11}$. Esta constatación invita a plantear, pues, la hipótesis de que su venida a Madrid pudo haber tenido lugar como consecuencia de su relación laboral con este célebre financiero genovés, con el que cabe la posibilidad de que hubiese establecido contacto en la propia Génova, ciudad no muy alejada de su Tenda natal.

Otros documentos de la década de 1630 nos lo muestran, sin embargo, realizando tratos mercantiles por cuenta propia con mercaderes de Niza, ciudad también perteneciente al ducado de Saboya. Por esta razón tampoco se puede desechar la hipótesis de que su venida a Madrid hubiese tenido lugar en seguimiento de sus negocios mercantiles y que, solo después de haberse instalado a la ribera del Manzanares, entrase en contacto con Juan Lucas Palavesin y decidiese ponerse a su servicio sin abandonar por ello sus tratos con mercancías.

Cualesquiera que fuesen las razones que le llevaron a abandonar las luminosas tierras de la Riviera franco-italiana donde vino al mundo por las más adustas del interior de Castilla, Bartolomé Arnolfo, después de haberse instalado en Madrid, se esforzó, no obstante, por alcanzar una plena integración en su «patria de adopción», olvidándose poco a poco de su Saboya de origen. Esta actitud no fue la que prevaleció entre los mercaderes extranjeros que residieron en Madrid en el siglo XVII, sino que por el contrario la mayoría de ellos concibieron su estancia en la capital de la Monarquía como meramente transitoria, aunque en el caso de algunos se prolongase, quizás a su pesar, durante muchos años e incluso hasta el momento de la muerte.

En el caso de Bartolomé Arnolfo abundan por el contrario los indicios que ponen de relieve su decidida apuesta por integrarse de forma irreversible en la sociedad madrileña. Una buena prueba la tenemos en su decisión de invertir en la compra de unas casas principales, abandonando la costumbre de tomar vivienda en alquiler, que fue la dominante entre los mercaderes extranjeros que residieron en Madrid en su época. Quiso además construirlas de nueva planta y en uno de los mejores barrios de la villa, en la calle de Carretas, donde también residieron otros mercaderes extranjeros, como el inglés Guillermo Pauley, quien, no obstante, lo hizo en régimen de alquiler ${ }^{12}$. Sabemos que su construcción estaba a punto de concluirse en el año 1644, cuando contrató la obra de rejería ${ }^{13}$. Y, una vez acabadas, residió en ellas hasta su muerte, acaecida en febrero de 1650, al mismo tiempo que su hijo Diego Arnolfo, a quien cedió vivienda en el cuarto segundo

11. Se le llama «oficial mayor de Juan Lucas Palavesín» en AHPM, 6494-305, Madrid, 2-VII1635. Como «oficial mayor de sus libros» aparece identificado en contrato de obligación otorgado en Madrid, 22-VI-1637, en AHPM, 5374-461.

12. Diago Hernando, M.: «Mercaderes y financieros ingleses en Madrid en tiempos de la revolución y guerra civil inglesa», Anales del Instituto de Estudios Madrileños, 49 (2009), pp. 397-445.

13. AHPM, 7780-568, Madrid, 23-IV-1644. 
para que pudiese residir allí junto con su esposa Jerónima Zoalli. Tras su muerte, sin embargo, la necesidad de atender las demandas de sus acreedores precipitó la venta en pública subasta de dichas casas, que fueron rematadas por la autoridad judicial en Juan Bautista de Benavente, tesorero general del Consejo de Órdenes y depositario del Consejo de la Cámara, por el elevado precio de 30.000 ducados. Como consecuencia, su viuda, Francisca Álvarez de la Torre, hubo de acabar sus días fuera del edificio que con tanto esfuerzo había hecho construir su marido, constándonos por su testamento, otorgado en 1659, que su última morada estuvo en la calle de Juan de Alarcón, de la parroquia de San Martín ${ }^{14}$.

El afán por integrarse en la sociedad madrileña de Bartolomé Arnolfo lo detectamos también en los criterios que inspiraron la concertación de los matrimonios de sus tres hijos. En efecto, su hija Ana casó con un miembro del influyente grupo de los oficiales que prosperaron en Madrid a la sombra de la Monarquía, Francisco Carrillo, contador de resultas del rey, del que ya había enviudado en $1649^{15}$. Su hijo Diego, por su parte, contrajo matrimonio en 1644 con Jerónima Zoalli ${ }^{16}$, que era hija de Pedro Zoalli, individuo de origen italiano que fue secretario del rey y regidor perpetuo de Madrid y estaba emparentado con la familia de origen genovés de los Sanguineto ${ }^{17}$. Gracias a este matrimonio, Diego Arnolfo, que desempeñó el cargo de contador de cuentas de la villa de Madrid, logró la plena integración en el estrecho círculo de la oligarquía madrileña del que ya formaban parte las familias de origen italiano de los Zoalli y los Sanguineto. Buena prueba de su exitosa integración en este medio sociopolítico nos la proporcionan los matrimonios que logró concertar para sus hijas. En concreto Antonia Arnolfo y Zoalli casó con Pedro Ignacio de Arce, caballero de Santiago, regidor de Madrid, y aposentador de la Real Casa de Castilla ${ }^{18}$. Por su parte, Jerónima de Arnolfo y Zoalli contrajo primeras nupcias con Don Pedro Juan de Frías, caballero de Santiago, y tras enviudar casó con el licenciado Alonso Fernández de Arce, abogado de los Reales Consejos ${ }^{19}$. Y, por fin, Juana de Arnolfo y Zoalli casó con otro abogado de los Reales Consejos llamado José de Ledesma y Goycochea ${ }^{20}$. Estas tres nietas de Bartolomé Arnolfo mostraron, pues, una marcada preferencia por enlazar con

14. Poder para testar otorgado por doña Francisca Álvarez de la Torre, viuda de Bartolomé Arnolfo, en AHPM, 6527-37, Madrid, 23-I-1659.

15. Consta por AHPM, 7516-411, Madrid, 10-VI-1649. Ella le sobrevivió muchos años, pues otorgó testamento en Madrid, 16-X-1685. AHPM, 11042-601.

16. Las capitulaciones matrimoniales en AHPM, 6220-46, Madrid 11-V-1644.

17. Pedro Zoalli era primo de Pedro Jácome Sanguineto, que lo nombró como uno de sus testamentarios. AHPM, 3390-1019, Madrid 13-X-1650.

18. AHPM, 11057-779, Madrid, 1-XII-1698.

19. AHPM, 11057-165, Madrid, 24-III-1698.

20. FAYARD, J.: Les membres du Conseil de Castille à l'epoque moderne (1621-1746). Droz, Gèneve, 1979, pp. 301 y 418. 
familias al servicio del aparato burocrático de la Monarquía, que en algunos casos habían puesto también el pie en el regimiento madrileño, en el que ya contaban, por lo demás, con parientes como Rafael Sanguineto, a quien tanto Antonia como Jerónima designaron para que fuese uno de sus testamentarios.

El elevado grado de arraigo de Bartolomé Arnolfo en la sociedad madrileña lo encontramos también reflejado en la total ausencia de cualquier tipo de alusión en sus disposiciones testamentarias a su tierra de origen, o a familiares que hubiesen podido quedar en ella ${ }^{21}$. Esta omisión resulta bastante llamativa pues tal género de alusiones eran habituales en los testamentos otorgados en esta época por los mercaderes extranjeros residentes en Madrid. Nada más lógico, por consiguiente, que tras su muerte, el 19 de febrero de 1650, se procediese a darle sepultura en la villa del Manzanares en la capilla de Nuestra Señora de la Concepción del convento de Nuestra Señora del Carmen Calzado ${ }^{22}$, aunque la misma no llegó a consolidarse como mausoleo familiar, pues al morir su viuda en 1659 sus restos mortales fueron depositados en la capilla de Nuestra Señora de la Buena Ventura de la iglesia del monasterio de San Basilio Magno ${ }^{23}$.

Aunque Bartolomé Arnolfo alcanzó un grado de integración en la sociedad madrileña muy superior al de la mayoría de sus colegas extranjeros dedicados al comercio y a las finanzas en la villa y Corte durante el siglo xviI, su figura ofrece, no obstante, la particularidad de que no alcanzó apenas influencia en el escenario político madrileño, ni en la Corte ni en el regimiento. Ciertamente el papel que desempeñó como financiero al servicio de destacados miembros del aparato burocrático de la Monarquía y de la propia Hacienda Regia, en calidad de asentista, pudo asegurarle por vía indirecta una cierta influencia política. Pero su promoción en el terreno socioeconómico no fue lo suficientemente rápida como para permitirle llegar a adquirir para sí mismo, por compra o por merced, un oficio de regidor de Madrid u algún oficio de los muchos que conformaban el aparato de gobierno central de la Monarquía con sede permanente en la villa del Manzanares. En esto se diferenció de los más afortunados miembros del grupo de los hombres de negocios italianos, con los que mantuvo muy estrechos contactos. Pero lo que no logró para él en persona sí supo asegurárselo a sus hijos, que gracias a sus matrimonios pasaron a quedar plenamente integrados en el medio sociopolítico de las familias con representación en el regimiento madrileño y en el aparato burocrático de la Monarquía.

No vamos a entrar aquí a profundizar en la caracterización del medio social en el que estuvo integrado nuestro personaje, ni de su mentalidad y modo de vida. Nos limitaremos a indicar que siguió un régimen de vida propio de las personas

21. El testamento en AHPM, 3390-244, Madrid, 14-II-1650.

22. Acta de entrega del cadáver al prior del convento, en Madrid, 19-II-1650 en AHPM, 7592-206.

23. AHPM, 6537-37, Madrid, 23-I-1659. 
de posición acomodada, aunque de condición no aristocrática. Así, fue propietario de un coche y de caballos para los que regularmente adquirió cebada y paja, que le solían proporcionar vecinos de Paracuellos del Jarama o Vicálvaro. Por su parte, panaderos de Vallecas a los que con regularidad adelantaba dinero le surtían de pan cocido a lo largo de todo el año, entregándoselo en su casa dos veces por semana. Que el tren de vida que consideraba apropiado para una persona de su rango resultaba costoso nos lo confirma el compromiso que adquirió cuando concertó el matrimonio de su hijo Diego con Jerónima Zoalli en 1644, obligándose a entregar en adelante a la nueva pareja en concepto de alimentos 1.000 ducados al año ${ }^{24}$. Por fin, también interesa hacer constar que, además de vivir de forma acomodada y con cierto lujo, debió formar parte del reducido grupo de personas con inquietudes culturales que tenían gran afición por la lectura y el estudio. Así lo sugiere al menos la composición de la bien surtida biblioteca que poseía en el momento de su muerte, en la que había numerosos títulos de muy variadas materias, y en diversas lenguas, con predominio de los escritos en italiano, pero con notable presencia también de otros en latín, en castellano, y uno en francés, los Essais de Montaigne ${ }^{25}$.

\section{LA ACTIVIDAD MERCANTIL}

Desde que tenemos noticias de la presencia de Bartolomé Arnolfo en Madrid lo encontramos dedicado a la práctica del comercio a escala internacional. En su etapa más temprana aparece interesado en la negociación con mercancías en puertos del sur de Francia, para la que contó con la colaboración de compatriotas residentes en Niza. Uno de ellos era a comienzos de la década de 1630 Antonio Massini, quien envió a Marsella ciertas mercancías a un mercader llamado Juan German para que este las vendiese por cuenta de nuestro personaje $\mathrm{e}^{26}$.

En esta misma época también lo encontramos ocupado en la exportación de mercancías a Inglaterra, para lo cual contó con la colaboración de correspondientes residentes en Londres y en Alicante, puerto de embarque de las mercancías destinadas a dicha isla. En la capital inglesa recurrió a los servicios de Juan de Lavaria, que vendió con anterioridad a 1636 en dicha plaza mercancías que le eran enviadas por cuenta suya ${ }^{27}$, y de Natan Wright (Nataniel Ruit), hermano de

24. Según capitulaciones matrimoniales en AHPM, 6220-46, Madrid 11-V-1644.

25. Relación pormenorizada de los títulos que componían su biblioteca en el inventario post mortem de su hacienda en AHPM, 3390-550.

26. Juan German envió después el dinero obtenido de la venta de dichas mercancías al propio Massini. Luego Bartolomé Arnolfo otorgó poder al genovés Juan Benito Spinola para cobrar dicho dinero. AHPM, 5266-152, Madrid, 1-VI-1632.

27. AHPM, 7177-204, Madrid, 25-I-1636. Carta de poder al alférez Pablo del Campo Rebolledo, 
un destacado financiero inglés residente en Madrid llamado Benjamín Ruit ${ }^{28}$, a quien en 1636 otorgó poderes para recibir todas las mercancías que por cuenta suya le fuesen remitidas desde Alicante por Juan Bautista Truco, en particular aceites, almendras y anís ${ }^{29}$.

En Madrid, al igual que hicieron otros muchos mercaderes italianos allí afincados después de que la definitiva instalación de la Corte convirtiese a esta villa en el principal centro de consumo suntuario del reino, actuó como proveedor de tejidos de lujo a mercaderes de sedas madrileños, asentados en la puerta de Guadalajara $^{30}$. Pero los productos textiles y de mercería con los que trató no los destinó en exclusiva al mercado madrileño, pues también tenemos constancia de que trató de darles salida en ciudades andaluzas ${ }^{31}$. Más esporádicamente negoció con otras mercancías que le eran enviadas desde Italia, a veces por encargo de mercaderes madrileños. Es el caso de los reputados espejos y cristales de Venecia, que en 1643 hizo traer por encargo del mercader madrileño Diego del Campo de esta ciudad italiana, con la que mantenía frecuentes contactos por razón de sus operaciones de exportación de lanas ${ }^{32}$.

Otros documentos nos lo muestran implicado en operaciones con otras muy variadas mercancías que seguían rutas muy diversas. Por ejemplo, participó en operaciones de venta de pescado, realizadas en compañía con su correspondiente en Alicante, Juan Bautista Truco, encargado de dar salida a la mercancía en este puerto levantino ${ }^{33}$. Se interesó por el trato con ganado vacuno, como demuestra una noticia del año 1635 sobre la venta que efectuó, junto con un tal Francisco García, vecino de Los Arcos, de 25 vacas a dos vecinos de Navalcarnero y uno de El Álamo, por un precio de 3.900 reales $^{34}$. También negoció con productos

residente en Madrid y de partida para Londres, para que cobrase de Juan de Lavaria las cantidades que hubiese ingresado por ventas de mercancías efectuadas por cuenta de Bartolomé Arnolfo.

28. Sobre este individuo Vid. Diago Hernando, M.: «Mercaderes y financieros ingleses en Madrid en tiempos de la revolución y guerra civil inglesa», Anales del Instituto de Estudios Madrileños, 49 (2009), pp. 397-445.

29. AHPM, 7177-118, Madrid, 16-I-1636.

30. A Mateo de Velasco vendió en 1639 tejidos de lujo por valor de 19.778 reales. AHPM, 370156, Madrid, 16-I-1639. A este mismo vendió en 1643 terciopelos y chamelotes por valor de 19.120 reales. AHPM, 7779-882, Madrid, 16-XI-1643. A Domingo de Campos le vendió en 164812 piezas de chamelotes por 11.572 reales de vellón. AHPM, 7208, Madrid, 14-V-1648.

31. Contrato firmado con un arriero para que le llevase desde Madrid a Sevilla o Carmona seis cajas de hilo blanco, en AHPM, 3704-529, Madrid, 21-IV-1642.

32. AHPM, 7779-925, Madrid, 1-XII-1643. Diego del Campo se obliga a pagar a Bartolomé Arnolfo, en 4 pagas de 3 en 3 meses, 10.976 reales de plata de resto del precio, derechos y gastos de una partida de espejos y vidrieras cristalinas, traída de Venecia.

33. AHPM, 3702-550, Madrid, 30-X-1640. Cuentas de liquidación de la correspondencia habida entre Bartolomé Arnolfo y Juan Bautista Truco, padre, difunto.

34. AHPM, 6494-305, Madrid, 2-VII-1635. 
tintóreos como el añil, utilizado en la manufactura pañera, que en 1643 hizo transportar desde Madrid a Segovia, para que se entregase a Melchor de Zumárraga, que era entonces su correspondiente en esta ciudad para sus operaciones de compra de lanas ${ }^{35}$. Desconocemos cuál era la procedencia de este añil, pero es probable que fuese de origen americano. Y esto nos lleva a plantearnos la cuestión de si tomó parte también en el lucrativo negocio del comercio con América. No disponemos de referencias concluyentes al respecto, aunque sabemos que mantuvo una estrecha relación de negocios con un genovés residente en Sevilla, Juan César Arpe. En 1644 hizo transportar de Madrid a Cádiz 10 fardos de pelo de camello blancos, que bien podían ir destinados a América ${ }^{36}$. Y, por fin, en 1643 su hijo Diego tenía previsto realizar un viaje al continente americano, en el que es probable que realizase operaciones comerciales por cuenta propia, del mismo modo que se proponía realizarlas por cuenta de otros mercaderes, residentes en Sevilla y Cádiz. De estas últimas da testimonio un documento otorgado por Bartolomé Arnolfo en que salió como fiador de su hijo, obligando su propia hacienda y crédito como garantía de que este daría buena cuenta con pago de las mercancías que le fuesen entregadas por otros mercaderes para llevar a vender a América, y de todas las operaciones mercantiles y financieras que realizase por cuenta de ellos en territorio americano ${ }^{37}$. Este viaje de negocios, por otra parte, no debió constituir un hecho aislado en la trayectoria de Diego Arnolfo, pues en 1642 ya había hecho registrar en Cádiz a su nombre barras de plata que habían venido de América en un galeón de la carrera de Indias, aunque después declaró que, pese a haberlas registrado a su nombre, dichas barras de hecho pertenecían a un vecino de Sevilla llamado Antonio Ruiz de Ocharcoaga ${ }^{38}$.

En suma, por tanto, dispersas informaciones extraídas de los protocolos notariales madrileños nos confirman que Bartolomé Arnolfo fue un mercader con actividad muy diversificada, con intereses en numerosos productos y rutas, y que contaba con una compleja red de correspondientes repartidos por las principales plazas de la Europa Occidental, tales como Londres, Sevilla, Alicante o Niza, además de las italianas. Pero, según todos los indicios, fue la lana fina del ganado trashumante, comprada en Castilla y exportada a Italia, la mercancía que mayor relevancia alcanzó en los negocios mercantiles de nuestro personaje durante sus años de estancia en Madrid. A ella vamos a dedicar por consiguiente nuestra atención a continuación.

35. AHPM, 7779-501, Madrid, 22-VI-1643. Contrato para el transporte de dos cajas de añil.

36. AHPM, 7781-1429, Madrid, 24-XII-1644.

37. AHPM, 7779-116, Madrid, 9-II-1643.

38. AHPM, 7781-1448, Madrid, 30-XII-1644. 


\section{Comercio de EXPORTACión DE LANAS FinAS}

Las primeras noticias encontradas sobre la participación de Bartolomé Arnolfo en el comercio lanero datan de los años finales de la década de 1620. En concreto en 1629 obtuvo licencia para exportar 65 sacas de lanas y añinos del partido de Villanueva de la Fuente, y en los siguientes años continuó exportando lanas de este mismo partido y del de Villanueva de los Infantes, que no se contaban entonces entre las de máxima calidad destinadas a la exportación ${ }^{39}$.

A partir de 1634, sin embargo, su interés se fue orientando de forma cada vez más decidida hacia lanas de superior calidad, pues en ese año obtuvo licencia para exportar 140 sacas de lana y 30 de añinos, de Segovia o Villacastín. Conforme avanzamos en la década de 1630 se incrementa el número de noticias sobre compras de grandes partidas de lana segoviana, que terminó consolidándose como el principal tipo de lana con el que negoció a partir de fines de esa década. Pero no por ello abandonó del todo la comarca de Villanueva de los Infantes y Villanueva de la Fuente, en la actual provincia de Ciudad Real, pues en 1639 hizo transportar desde allí a Alicante 36 sacas de lana fina en carretas de mulas ${ }^{40}$.

Durante el siglo Xvir las lanas segovianas fueron universalmente reconocidas como las de mayor calidad y alcanzaron por consiguiente los máximos precios entre cuantas se exportaron desde la Corona de Castilla. Especialmente apreciada fue la variante conocida con el nombre de segoviana-leonesa, obtenida del esquileo de las cabañas de mayor reputación, que aprovechaban durante los veranos los finos pastos de la montaña de León ${ }^{41}$.

Fueron muchos, y de muy variado perfil sociopolítico, los productores de este tipo de lanas con los que negoció Bartolomé Arnolfo la compra de sus pilas, para después lavarlas en el lavadero que con este objeto adquirió en Villacastín y finalmente transportarlas a Alicante, previo paso por Carabanchel

39. Noticias sobre sus exportaciones de lanas en 1629 en AHPM, 4660, 22-VI-1629. En 1631 obtuvo licencia para exportar 100 sacas de lana de 10 arrobas del partido de Villanueva de los Infantes (AHPM, 4660, 13-VIII-1631), y en 1633 para 260 sacas de 10 arrobas de lana lavada de Villanueva de la Fuente, más otras 20 sacas voluntarias, 9 sacas de añinos sucios de Molina, y una saca voluntaria, y 22 sacas de lana lavada de Segovia, y dos voluntarias (AHPM, 4673, 6-VII-1633).

40. Contrato con los carreteros en Madrid, 30-VIII-1639, en AHPM, 3701-284.

41. Referencias sobre la tipología de las lanas que se comercializaron en Castilla durante el siglo XVII en Diago Hernando, M.: «El mercado lanero en la región soriana durante los siglos XVI y XVII: Tipología y destino de las lanas», Celtiberia, 96 (2002), pp. 47-88. Una visión global sobre el comercio lanero en Castilla en la Edad Moderna en PhILliPs, C. R. y W. D.: Spain's Golden Fleece. Wool Production and the Wool Trade from the Middle Ages to the Nineteenth Century. The Johns Hopkins University Press, Baltimore, 1997. (Traducción española: El toisón de oro español. Producción y comercio de lana en las épocas medieval y moderna. Junta de Castilla y León, Valladolid, 2005). 
Bajo, donde se almacenaban para que allí las cargasen los carreteros. Entre ellos cabe destacar, por la reputación y tamaño de su cabaña, a los miembros de la familia Mesía de Tovar, originarios de Villacastín, de los que nos ocuparemos con detalle en el siguiente epígrafe. Otros señores de cabañas de gran tamaño y reputación con los que negoció fueron, por ejemplo, el duque de Béjar ${ }^{42}$, y varios regidores de la ciudad de Segovia, como Joseph de San Román o Blasco Bermúdez de Contreras ${ }^{43}$. Pero no todas las compras que efectuó en la ciudad del Eresma fueron de pilas de grandes dimensiones, pues también realizó allí operaciones de menor envergadura, como las concertadas en 1647 con Pedro Manuel de Azcárate, a quien adquirió 1.100 arrobas de lana y añinos ${ }^{44}$, o con los testamentarios de Don Antonio Fernández Miñano, a los que compró primero una partida de 500 arrobas y luego otra de $100^{45}$. Y otro tanto cabe decir de sus tratos con los ganaderos de Villacastín, que rivalizaban con los de la propia ciudad del Eresma por el tamaño y reputación de sus cabañas, pues también en ocasiones se tradujeron en operaciones de modesta envergadura, como la concertada en 1649 con Catalina Márquez de Prado, viuda de Don Pedro Juan de Pedraza, que le vendió 280 arrobas de lana para devolverle 15.680 reales que le había prestado ${ }^{46}$.

Un segundo grupo de productores de lana fina segoviana con los que trató tenían su asiento en las comarcas rurales del entorno de la villa de Ayllón. Eran propietarios de cabañas de gran tamaño, aunque con reputación ligeramente inferior a la de las grandes cabañas de la ciudad de Segovia y sus antiguas aldeas de El Espinar y Villacastín. Buenos ejemplos de este tipo de ganaderos nos los proporcionan diversos miembros de las familias Sanz Cadima y Merino, a los que adquirió entre los años 1646 y 1649 cantidades que oscilaron entre las 700 y las $2.200 \operatorname{arrobas}^{47}$. Con frecuencia cerró sus tratos con ellos en Madrid, a donde se

42. AHPM, 5375-299, Madrid, 2-IV-1638. Contrato de compra de 3.300 arrobas de lana. Poco tiempo después el duque de Béjar vendió sus ganados, que hacía poco había adquirido por sendas compras de dos propietarios segovianos, a unos vecinos de Barco de Ávila, que siguieron vendiendo las lanas varios años a Bartolomé Arnolfo.

43. AHPM, 6525-433, Madrid, 29-III-1647. Contrato de compra de 5.000 arrobas lana y añinos.

44. AHPM, 6525-458, Madrid, 1-IV-1647.

45. AHPM, 6525-467, Madrid, 3-IV-1647, y 6525-524, Madrid, 8-IV-1647.

46. AHPM, 7591-37, Madrid, 12-I-1649.

47. AHPM, 7783-261, Madrid, 6-V-1646. Contrato de compra a Gregorio Sanz Cadima y Merino, vecino de Villacadima, de 850 arrobas de lana y añinos. Sobre la compra a este mismo en compañía con Melchor Merino, vecino de Villacadima, y otro vecino de El Grado, aldea de Ayllón, de 755 arrobas de lana en 1647, Vid. AHPM, 7515-219, Madrid, 7-IV-1648. El contrato de venta por estos tres mismos ganaderos de 2.200 arrobas de lana y añinos del esquileo de 1648 en AHPM, 7590-435, Madrid, 9-V-1648. Contrato de venta por Gregorio Sanz Cadima de 1.000 arrobas del esquileo de 1649 en AHPM, 7591-441, Madrid, 17-V-1649. 
desplazaban para resolver negocios, pero en otras ocasiones delegó esta tarea en su correspondiente en la ciudad de Segovia, Melchor de Zumárraga ${ }^{48}$.

Un tercer grupo de ganaderos que le proveyó de lanas finas «segovianas» estuvo constituido por vecinos de varias villas y aldeas abulenses y salmantinas próximas a la Sierra de Gredos. Se trató, una vez más, de ganaderos de muy diverso perfil, entre los que había algunos grandes propietarios, como Francisco Martínez de las Heras, vecino de El Barco de Ávila, a quien en 1637 compró 3.600 arrobas de lana ${ }^{49}$, o don Álvaro Villapecellín Carvajal y Loaisa, de la misma vecindad, que en mayo de 1646 le vendió su pila estimada en unas 800 arrobas $^{50}$. Pero también abundaron los pequeños propietarios que apenas lograban reunir las 300 arrobas por año ${ }^{51}$.

Otro importante ámbito productor de lanas finas en el que Bartolomé Arnolfo actuó fue el las sierras conquenses. De él nos ocuparemos con más detalle en el apartado dedicado al análisis de su relación de negocios con uno de los principales señores de ganado trashumante del partido mesteño de Cuenca a mediados del siglo xvir, el regidor Alonso Muñoz de Castilblanque.

Por fin, un último ámbito en el que encontramos documentada su actividad como mercader lanero es el de la actual región de Extremadura. Así, en 1640 compró a una decena de pequeños propietarios de la villa de Castuera un total de 480 arrobas de lana blanca, que, no obstante, no le fueron entregadas por estos en el plazo estipulado ${ }^{52}$. Y, años más tarde, sabemos que continuaba utilizando como agente de compras en esta región a un vecino de Zalamea llamado Pedro de Ferreras Cenizales ${ }^{53}$.

48. Noticia de una compra de 332 arrobas del esquileo de 1642 a Melchor Merino, vecino de Grado, por Melchor de Zumárraga en AHPM, 7779-533. En julio de 1643 este último debía a Bartolomé Arnolfo 525.952 mrs. por alcance en el ajuste de cuentas de la correspondencia que entre ambos habían tenido. AHPM, 777-549.

49. AHPM, 5374-247, 31-III-1637. El precio acordado fue ligeramente inferior a los que nos consta que obtuvieron por sus lanas algunos señores de ganados segovianos, que estuvieron en torno a 36 y 37 reales por arroba.

50. AHPM, 7783-273, Madrid, 7-V-1646.

51. En Navalperal de la Ribera, aldea de Piedrahita, compró en 1646 a Diego García Moreno 200 arrobas de lana y añinos (AHPM, 7783-265, Madrid, 7-VI-1646), y a Joseph Joseph Hernández 100 arrobas de lana y 30 de añinos (AHPM, 7783-341, Madrid, 25-V-1646). En Béjar compró a Francisco Díaz de Velasco 110 arrobas. AHPM, 7783-359, Madrid, 3-VI-1646. En la villa de El Boyo adquirió en 1648 de Juan de Solís 320 arrobas de lana y 80 de añinos. AHPM, 7590-416, Madrid, 6-V-1648. 495.

52. Consta por carta de poder de Bartolomé Arnolfo, en Madrid 19-VI-1643, en AHPM, 7779-

53. AHPM, 7783-699, Madrid, 13-XI-1646. Poder de Bartolomé Arnolfo a Pedro de Ferreras Ceniçales, vecino de Zalamea. A este mismo otorgó poder en 21-VII-1643 para cobrar las 480 arrobas de lana compradas en 1640 a los vecinos de Castuera, y que todavía no habían entregado. AHPM, 7779-565. 
Por contraste, no tenemos constancia de que invirtiese en la compra de lanas finas sorianas, que, tras las segovianas, eran en aquella época las más apreciadas en los mercados exteriores, alcanzando por ello un precio muy superior al de las de Cuenca. Esta ausencia de noticias llama la atención, pues nuestro personaje mantuvo relaciones de negocios con sorianos instalados en Madrid que sirvieron como agentes de compras para otros destacados exportadores de lanas reidentes en la villa del Manzanares, como Juan García del Pozo ${ }^{54}$. El hecho de que en aquellos momentos las lanas de las sierras sorianas fuesen exportadas de forma preferente por vía marítima a través de los puertos del Cantábrico, o por la vía terrestre a través de Navarra hacia Francia, quizás le disuadió de negociar con ellas, dado que el mercado hacia el que él prefirió dirigir sus exportaciones fue el italiano, abastecido desde los puertos del Mediterráneo, en especial Alicante, y en menor grado Cartagena y Almería.

Las estrategias de contratación puestas en práctica por Bartolomé Arnolfo con los ganaderos estuvieron bastante diversificadas. Por un lado, a algunos les adelantó importantes cantidades de dinero que habían de devolverle mediante la entrega de sus lanas y añinos de uno o varios esquileos. Así lo comprobaremos al analizar sus tratos con los Mesía de Tovar y el conquense Alonso Muñoz de Castilblanque. Pero, a la inversa, otros ganaderos, en algunos casos de talla relativamente modesta, le concedieron a él aplazamientos de pago, accediendo a retrasar el cobro del total o de una parte del valor de las lanas que le vendieron hasta varios meses después de su entrega. $Y$, en la etapa final de su vida, sus problemas de falta de liquidez le impidieron en ocasiones efectuar puntualmente los pagos a dichos ganaderos en los plazos previstos. Lo prueba el hecho de que entre los acreedores que acudieron al concurso abierto tras su muerte hubo varios señores de ganados de la sierra segoviana del entorno de Ayllón ${ }^{55}$.

Desde que tenemos noticias sobre la presencia de Bartolomé Arnolfo en Madrid nos consta que compraba lanas para exportar, y en todo momento las

54. Mantuvo relación con Juan García del Pozo por razón de un asiento que concertó con la Real Hacienda en 1642. Vid. AHPM, 7778-355, Madrid, 31-X-1642. Y 7779-872, Madrid, 13-XI1643. Información sobre los negocios de este soriano afincado en Madrid en Diago Hernando, M.: «Juan García del Pozo y las relaciones económicas entre Madrid y Soria en el siglo XVII», Anales del Instituto de Estudios Madrileños, 39 (1999), pp. 183-212. Sobre su papel como agente de compras de lanas para exportadores flamencos residentes en Madrid Vid. Diago Hernando, M.: «Actividad mercantil y financiera de los hombres de negocios flamencos en Madrid a mediados del siglo XVII», Anales del Instituto de Estudios Madrileños, 41 (2001), pp. 165-206.

55. Gregorio Sanz Cadima, Melchor Merino, vecino de Villacadima, y Melchor Merino, vecino de El Grado, Tierra de Ayllón, otorgan poder a Lorenzo Martínez, vecino de Madrid, para el pleito y concurso de acreedores a los bienes de Bartolomé Arnolfo, para reclamar 22.016 reales que les quedó debiendo por escrituras de obligación, procedidas de ventas de lanas. AHPM, 7596-1276, Madrid, 12-XI-1654. 
destinó de forma preferente a Italia. Su puerto preferido de embarque fue el de Alicante, donde mantenía relaciones de correspondencia con varios mercaderes genoveses allí residentes, entre los que destacan Juan Bautista Truco, Juan Agustín Ansaldo y Juan Bautista Musiteli, que fueron los encargados de buscar barcos para transportarlas a los puertos italianos siguiendo las instrucciones que él les daba. De forma más excepcional también embarcó lanas en el puerto de Almería ${ }^{56}$. Pero por contraste apenas tenemos noticias de la concertación de embarques de lanas en los puertos del Mar Cantábrico, y todas las reunidas se refieren a cantidades muy pequeñas ${ }^{57}$.

Sin duda disponía de contactos más fiables en Italia para dar allí salida a las lanas que adquiría en territorio castellano. En alguna ocasión recurrió a mercaderes italianos residentes en Madrid para que ellos se encargasen de dar salida a la mercancía recurriendo a sus correspondientes residentes en Italia. Lo hizo en 1637, cuando encargó al florentino Nicolás Albici de la gestión de la venta en Florencia de 37 sacas de lana de Villacastín que él había enviado a Juan Bautista Truco a Alicante, con la orden de que las embarcase para conducirlas bajo el nombre de Nicolás Albici, hasta Livorno, donde habrían de entregarse a Vicencio Corsini y Juan Bautista Bifi. La razón por la que las lanas se habían de embarcar bajo este nombre era para facilitar la negociación con ellas después de su llegada a Livorno, ya que este mercader florentino se comprometió a utilizar su red de correspondientes en Italia para que las sacas fuesen conducidas a Florencia, y se vendiesen allí «con toda la ventaja posible, conforme las órdenes que Arnolfo le diere». El saboyano a cambio le abonaría los derechos de encomienda acostumbrados ${ }^{58}$.

Ese mismo año de 1637, sin embargo, Bartolomé Arnolfo se hizo cargo de la venta de 133 sacas de lana pertenecientes a la familia de los Mesía de Tovar en la ciudad de Venecia, donde los mercaderes genoveses Francisco Taliacarne y Juan Francisco Cassion se encargarían de buscar compradores para ellas. Otras noticias nos confirman que estos dos individuos residentes en la ciudad de los canales, y otros mercaderes genoveses residentes en la propia Génova, como Juan Benito Espínola y Andrea Taliacarne, fueron socios de Bartolomé Arnolfo en varias grandes operaciones de exportación de lanas, los cuales se encargaron de

56. En el verano de 1648 hizo transportar gran número de sacas desde Carabanchel a Almería, según demuestran varios contratos con carreteros en AHPM, 7590.

57. En 1642 dos arrieros vascos le llevaron desde Segovia a Bilbao 14 cargas de lanas y añinos lavados, que habían de entregar en la capital vizcaína a Antonio de Lorenzo. AHPM, 7778-335, Madrid, 5-X-1642. A este mismo individuo remitió en 1646 desde Segovia 16 sacas de lana fina segoviana que fueron embarcadas en una nave con rumbo a Flandes, aunque luego surgieron problemas con ellas porque no fueron entregadas a sus correspondientes. Noticia e AHPM, 7591-860, Madrid, 14-IX-1649.

58. AHPM, 5374-598, Madrid, 12-VIII-1637. 
la venta de las mismas en las plazas de Génova y Venecia, y participaron en los beneficios en proporción a la inversión realizada en cada caso ${ }^{59}$.

Para conocer mejor el funcionamiento del negocio de exportación de lanas de Bartolomé Arnolfo habría que profundizar, por fin, en la reconstrucción de su relación con otro destacado mercader genovés residente en Granada, Antonio Taliacarne, quien, según indicios, pudo haber sido su socio en más de una empresa, y al que al parecer quedó adeudando bastante dinero en el momento de su muerte.

Por otra parte, se ha de hacer constar que, aunque nuestro personaje fue ante todo un exportador volcado hacia el mercado italiano, en la etapa final de su vida optó en más de una ocasión por desprenderse de las lanas dentro del propio territorio castellano, antes de proceder a su embarque, vendiéndolas a otros mercaderes exportadores residentes en Madrid. Es lo que hizo, por ejemplo, en 1645 con las lanas y añinos procedentes del esquileo de sus propios ganados, que ese ejercicio ascendieron a 3.203 arrobas, que vendió al asentista portugués Andrés Gómez Dávila ${ }^{60}$.

\section{Prestamista de los Mesía de Tovar, grandes ganaderos de Villacastín}

La de los Mesía de Tovar fue una de las principales familias de señores de ganados trashumantes en la Castilla del siglo xviI, propietaria de una de las cabañas de mayor tamaño y reputación del reino. Originaria de Villacastín, antigua aldea de Segovia, había protagonizado un espectacular proceso de ascenso social y político, que la llevó a ocupar una influyente posición en el aparato de gobierno y administración de la Monarquía durante los reinados de los Austrias menores ${ }^{61}$. Su elevada posición no la puso a salvo, sin embargo, de las penurias que la falta de liquidez hizo sufrir a muchas familias de la nobleza castellana a lo largo del

59. En 1648 Bartolomé Arnolfo, por ejemplo, remitió desde Almería a Génova a Francisco Taliacarne 153 sacones de añinos finos, en los que a él mismo le pertenecían cuatro partes de once, y las otras siete partes pertenecían a Francisco Taliacarne, Francisco Casion, y Juan Benito Espinola. En 1649, por su parte, hizo empleo de 5.474 arrobas de lana fina segoviana beneficiada en Villacastín, en las que entraban las procedidas del esquilo de sus ganados de ese año. De ellas 2.500 arrobas las había comprado por cuenta y orden de Francisco Taliacarne y Francisco Casion, vecinos de Venecia, y Juan Benito Espinola, vecino de Génova. Se remitieron todas a Venecia, dirigidas a Francisco Taliacarne y Francisco Casion, con orden de que se vendiesen a los precios corrientes. En 1649, por fin, remitió 28 sacones de lana fina a Andrea Taliacarne, vecino de Génova, todos por cuenta propia. Vid. AHPM, 9380-51 y 65, Madrid, 29-VIII-1653.

60. AHPM, 7783-171, Madrid, 15-III-1646. Carta de pago de Bartolomé Arnolfo, reconociendo haber recibido de Andrés Gómez Dávila 193.781,5 reales de vellón, más intereses, por el valor de 3.203 arrobas de lana y añinos, del esquileo de sus ganados del año 1645, que le había vendido a 60,5 reales arroba. El contrato de venta en Madrid, 5-V-1645, en AHPM, 7782-591.

61. Nos basamos en información extraída de protocolos notariales madrileños, pues no conocemos ningún trabajo monográfico dedicado a la reconstrucción de la trayectoria de esta familia. 
turbulento siglo XVII, marcado por el desorden monetario y el desbocado incremento de las necesidades financieras de una voraz Real Hacienda, que no escatimó en medios para extraer dinero de todos los grupos sociales del reino.

Desconocemos las circunstancias concretas que dieron lugar a que se desencadenase el grave proceso de endeudamiento de esta familia, premiada por la Monarquía con el título del condado de Molina de Herrera. Por el momento basta con partir de la constatación de que a mediados de la década de 1630 el primer conde de Molina de Herrera, y sus dos hijos, Don Pedro y Don Antonio, debían una importante cantidad de dinero a los financieros genoveses Juan Lucas Palavesín, residente en Madrid, y Juan Benito Espínola, residente en Génova. Para aquellas fechas Bartolomé Arnolfo trabajaba al servicio del primero, como oficial de sus libros, y pensamos que debió ser esta circunstancia la que le brindó la ocasión de iniciar una estrecha relación de negocios con esta familia, que se prolongó hasta el final de sus días.

Los primeros tratos de Bartolomé Arnolfo con los Mesía de Tovar de los que hemos encontrado rastro documental datan del verano de 1637, cuando, para amortizar parte de la deuda que el primer conde de Molina y sus hijos habían contraído con Juan Lucas Palavesín y Juan Benito Espínola, se acordó que se empleasen las lanas y añinos de su cabaña de ese ejercicio, y que fuese el propio Arnolfo el encargado de su venta en Italia. Conforme al contrato firmado en Madrid el 30 de agosto de 1637, el saboyano había de hacerse cargo de la conducción de las 133 sacas de lana lavada hasta el puerto de Alicante, donde su correspondiente, Juan Bautista Truco, debería embarcarlas con destino a Venecia, consignadas a Francisco Taliacarne y Juan Francisco Cassion. Estos dos se encargarían de darles salida en el mercado veneciano, siguiendo las instrucciones que les diese el saboyano, y deberían después transferir el dinero obtenido de la venta, previo descuento del importe de los derechos de encomienda y de los gastos de flete, a la ciudad de Génova, a poder de Juan Benito Espínola, para con él amortizar parte de la deuda que el conde de Molina y sus hijos tenían entonces contraída con este y con Juan Lucas Palavesín. Bartolomé Arnolfo, por su parte, había de ser compensado con una comisión del $2 \%$ sobre el precio obtenido por la venta de las lanas en Venecia ${ }^{62}$.

Desconocemos cuál fue el resultado final de esta operación ${ }^{63}$. Pero es seguro que con la misma no se pudo saldar en su integridad la deuda que los Mesía de

62. AHPM, 5374-649, Madrid, 30-VIII-1637.

63. Todavía en unas cuentas que Bartolomé Arnolfo ajustó con los hermanos Mesía de Tovar en Madrid, 8-IX-1641, se hizo constar que de la cantidad total que los primeros le adeudaban se había de descontar lo procedido de la venta en Venecia de las referidas 133 sacas de lana. Vid. AHPM, 5379-543. 
Tovar tenían contraída con Juan Benito Espínola y Juan Lucas Palavesín. Así nos lo confirma una escritura que este otorgó en Madrid, el 7 de octubre de 1639, por la que cedió a Bartolomé Arnolfo el derecho a cobrar de los dos hijos del primer conde de Molina, ya difunto, cuatro partidas que sumaban 26.493 escudos, 6 sueldos y 6 dineros $^{64}$. Se trataba de una más de las muchas operaciones de compensación practicadas por los financieros, que en este caso demuestra que Bartolomé Arnolfo estaba emancipándose respecto al que había sido su patrón, y se encontraba ya en condiciones de asumir la realización por cuenta propia de arriesgadas operaciones financieras. Y, por lo que toca a Juan Lucas Palavesín, parece que marcó el punto final de sus tratos con la familia Mesía de Tovar, puesto que no hemos encontrado en la documentación noticia de que les volviese a efectuar nuevos préstamos. Por el contrario, a partir de esta fecha los protocolos notariales rebosan de noticias de adelantos de grandes cantidades de dinero efectuados por Bartolomé Arnolfo al segundo conde de Molina, y a su hermano Antonio, que se prolongaron hasta el propio momento de la muerte del saboyano.

Durante bastantes años estos adelantos se los estuvo efectuando con la condición de que para su devolución los Mesía de Tovar quedasen obligados a entregarle las lanas y añinos de su cabaña. Pero a diferencia de lo que se hizo en 1637, cuando las lanas se llevaron a vender a Venecia por cuenta de los Mesía de Tovar, limitándose Arnolfo a actuar como intermediario comisionista que percibía un porcentaje fijo del producto de su venta, a partir de 1638 el saboyano asumió por su propia cuenta la negociación con la mercancía en Italia, embolsándose directamente los beneficios obtenidos de su venta.

En concreto, los Mesía de Tovar comprometieron la entrega a Bartolomé Arnolfo de 5.000 arrobas del esquileo de sus ganados del año 1638 a cambio de recibir adelantados un total de 173.000 reales, en virtud de cuatro contratos de obligación que firmaron entre el 9 de julio de 1637 y el 26 de enero de $1638^{65}$. Pero en todos estos contratos todavía se incluyó una cláusula disponiendo que la obligación de entregar las lanas cesaría en caso de que los Mesía de Tovar devolviesen el dinero que habían recibido prestado antes de una determinada fecha, indicada en el respectivo contrato. Esto demuestra, por tanto, que Bartolomé Arnolfo aprovechó los problemas de falta de liquidez que comenzaban a aquejar a estos reputados ganaderos segovianos para hacerse con el control de su pila en condiciones ventajosas. Y, dado que con el paso del tiempo dichos problemas de liquidez no se resolvieron sino que por el contrario se agravaron, su capacidad

64. АНPM, 5378-732.

65. AHPM, 5374-499, 574 y 867, y 5375-88. Por el primer contrato se vendieron 1.500 arrobas, a 33 reales; por el segundo 1.500 al mismo precio; por el tercero 1.000 arrobas a 35 reales; y por el cuarto y último 500 arrobas de lana, a 34 reales, y 500 de añinos, a 44 reales. 
de asegurarse la adquisición de esta prestigiosa pila en condiciones cada vez más favorables no hizo sino reforzarse.

Así, las lanas y añinos del equileo del año 1639 fueron vendidos por adelantado en julio de 1638, momento en que Bartolomé Arnolfo adelantó 316.000 reales de vellón $^{66}$. En el siguiente ejercicio, en octubre de 1639, habiendo muerto ya el primer conde de Molina, sus dos hijos, Pedro, segundo conde, y Antonio, volvieron a vender por adelantado al saboyano las 8.000 arrobas de lana que preveían obtener del esquileo de sus ganados en mayo de 1640 , a un precio fijo de 40 reales, con la condición de que todo el dinero se destinaría a amortizar la deuda contraída con él. En esta ocasión Bartolomé Arnolfo no quiso comprarles los añinos, pero también exigió que el producto de su venta se destinase a la amortización de dicha deuda ${ }^{67}$, la cual ya ascendía entonces a 486.463 reales de vellón y 23.000 reales en plata ${ }^{68}$. Finalmente la cantidad de lana obtenida por los dos hermanos en este ejercicio ascendió a 8.446 arrobas, que abonadas a un precio fijo de 40 reales por arroba contribuyeron a reducir la deuda en 337.840 reales de vellón. Pero la falta crónica de liquidez les llevó a continuar precisando constantes adelantos de dinero, que puntualmente les efectuó el saboyano, cargándoles unos intereses del $10 \%$ anual, de modo que la cuantía total adeudada se fue incrementando de forma significativa con el transcurso de los meses. Así, según el ajuste de cuentas de 17 de agosto de 1640 , ascendía ya a 567.248 reales, de los cuales 15.550 en plata ${ }^{69}$. A la amortización parcial de esta cantidad se destinaron las 8.648 arrobas de lana reunidas en el esquileo de 1641, que a 67 reales importaron 579.416 reales, más 303 arrobas 20 libras de añinos, que a 64 reales montaron 20.082 reales $^{70}$. Pero, pese a esta extraordinaria inyección de dinero, la deuda no quedó amortizada ya que en septiembre de 1641, después de descontado el valor de las lanas y añinos del último esquileo, los hermanos Mesía de Tovar todavía quedaron adeudando 361.884 reales de vellón y 16.594 reales de plata.

Entonces ambas partes llegaron a un acuerdo por virtud del cual los dos hermanos se comprometieron a vender a Bartolomé Arnolfo todas sus lanas y añinos de su cabaña en los cuatro años siguientes, hasta 1645, aunque se dejó

66. El contrato de venta en AHPM, 5376-579. Finalmente se entregaron 7.452 arrobas de lana, pagadas a 34 reales la arroba, y 1.170 arrobas de añinos, a 44 reales la arroba. AHPM, 5378-753.

67. AHPM, 5378-750, Madrid, 10-X-1639.

68. Según cuentas ajustadas en octubre de 1639 en AHPM, 5378-753.

69. AHPM, 5379-543. A esta deuda principal se sumaban otra de 33.000 reales de plata, por escritura de obligación en Madrid 14-III-1640, y otra de 26.493 escudos 6 s. 6 d. de oro de marco que los Mesía de Tovar deben pagar a Arnolfo por cesión que a favor de este había efectuado Juan Lucas Palavesín en 7-X-1639.

70. Según el ajuste de cuentas de Madrid, 8-IX-1641. Los añinos procedían todos de la cabaña del hermano mayor, el conde de Molina. Por lo que toca a las lanas, 4.101 arrobas procedían de los ganados del conde, y 4.547 arrobas de los de su hermano Antonio. 
libertad al saboyano para que, en caso de no interesarle la compra en cualquiera de los dichos ejercicios, pudiese abstenerse de quedarse con ellas, aunque debía declarar su intención con un año de antelación. En concreto los Mesía de Tovar quedaban obligados a ponerse en contacto con él durante el mes de julio de cada año, a partir de 1642, para consultarle si estaba dispuesto a adquirir la pila del siguiente esquileo. En caso de no estar interesado en su compra quedaban en libertad para venderla a quien quisiesen, pero tanto en uno como en otro caso, el producto íntegro de la venta debía destinarse a la amortización de la deuda. Bartolomé Arnolfo, por su parte, se comprometía a continuar efectuando a los dos hermanos los préstamos del dinero que necesitasen para asegurar el funcionamiento de sus explotaciones ganaderas, aunque les quedaba rigurosamente prohibido destinarlo a cualquier otro fin ${ }^{71}$.

Esta buena disposición del saboyano a seguir prestando dinero se la hizo recompensar, no solo mediante el cobro de un interés del 10\% anual, sino que también pasó a imponerles a los dos hermanos unas condiciones más desfavorables en la fijación del precio de sus lanas. En concreto, estos pasaron a hacerle una importante concesión, consistente en que del precio fijado para sus lanas por el sistema de atenencia, es decir remitiéndose al precio al que se les pagasen a otros señores de ganados segovianos que ellos podían elegir, siempre que no fuese el monasterio del Paular, se procedería a descontar 2,5 reales por arroba ${ }^{72}$. Se trató de una concesión que, según reconocieron explícitamente en los contratos, le hicieron voluntariamente en señal de reconocimiento por los grandes favores que les prestaba, por concederles espera para la devolución del dinero que le debían, y por estar dispuesto a continuar efectuándoles adelantos de dinero, sin los cuales no podrían garantizar la continuidad de sus explotaciones ganaderas ${ }^{73}$.

El problema de falta crónica de liquidez que padecieron el segundo conde de Molina y su hermano, les colocó, pues, en una posición de absoluta dependencia respecto a Bartolomé Arnolfo, quien pudo hacerse con su prestigiosa pila de lanas y añinos en unas condiciones ventajosas siempre que le interesó adquirirla. Pero este interés fue decayendo progresivamente, de forma que ya en 1644, aunque previamente se había comprometido por contrato a comprarles las lanas de ese

71. AHPM, 5381-597, Madrid, 8-IX-1641.

72. Más adelante este descuento se incrementó a 4,5 reales por arroba, y se aplicó también a las ventas de lanas efectuadas a otros mercaderes. En estos casos Bartolomé Arnolfo ingresaba el total del dinero obtenido de la venta de las lanas, pero compensaba a los Mesía de Tovar por una cantidad menor, después de aplicar el referido descuento o «refacción». Un ejemplo en el ajuste de cuentas de Madrid, 20-VII-1644, en AHPM, 7781-919. Más adelante el descuento llegó a seis reales por arroba, que fue el previsto en el contrato de venta adelantada de las lanas del esquileo de 1645, en AHPM, 7781-1023, Madrid, 18-VIII-1644.

73. Contrato de venta por adelantado de las lanas de los esquileos de 1643 y 1644 en AHPM, 7779-371, Madrid, 3-V-1643. 
esquileo, finalmente optó por no quedarse con ellas, y consintió en que se vendiesen a unos mercaderes portugueses, aunque continuó tomando parte activa en el proceso de fijación del precio, y cobró en su integridad el producto de su venta ${ }^{74}$. Y de este mismo modo se siguió procediendo en los siguientes ejercicios, en que también mercaderes portugueses se quedaron con las lanas.

En el año 1644, no obstante, no se juzgó suficiente destinar el producto de la venta de lanas y añinos para la amortización de la deuda, y Bartolomé Arnolfo llegó a un acuerdo con los Mesía de Tovar para que estos le vendiesen una parte importante de su cabaña y se destinase el producto de dicha venta a ese mismo efecto. Así lo comprobaremos más adelante.

Teniendo en cuenta todo esto, nada tiene de extraño que finalmente terminasen surgiendo fuertes tensiones en las relaciones entre Bartolomé Arnolfo y los Mesía de Tovar, que siguieron agravándose hasta el momento de la muerte del primero en febrero de 1650, y dejaron después como secuela un interminable proceso judicial. Así, en sus últimos años de vida el saboyano se vio involucrado en un agrio pleito contra los segovianos, después de que los dos hermanos le denunciasen por haberles cargado unos intereses usurarios en los préstamos y ventas de lanas que durante muchos años había concertado con ellos. Más en concreto, exigieron que se diese por nula una escritura de obligación que habían otorgado ante notario reconociendo que le adeudaban 765.345 reales, argumentando que tal cosa no era cierta, puesto que les había cobrado en los últimos años ilícitamente, «a título de intereses, refacciones en ventas de lanas y reducciones de moneda», grandes cantidades de dinero, que por consiguiente estaba obligado a restituirles. El proceso se sustanció ante los alcaldes de Corte, actuando como escribano Bartolomé de Salazar, pero, antes de que estos sentenciasen, las dos partes litigantes decidieron comprometer sus diferencias en manos de Juan de Solórzano, quien pronunció sentencia a favor de los hermanos Mesía de Tovar, de la que Bartolomé Arnolfo interpuso apelación ante el Consejo de Castilla, donde el pleito quedó estancado durante muchos años, pues siete años después de haber muerto el saboyano todavía no se había pronunciado sentencia ${ }^{75}$.

En conclusión, por tanto, podemos calificar a la relación de negocios que Bartolomé Arnolfo estableció con los Mesía de Tovar como fundamental en su trayectoria como mercader y financiero, no solo por la envergadura de las cuantías de dinero involucradas en sus tratos, sino también por el papel central que en los

74. Antonio Mesía de Paz vendió al asentista portugués Andrés Gómez Dávila en Madrid, 22-II1644. AHPM, 7780-193. Su hermano Pedro, conde de Molina, vendió en Madrid, 14-III-1644, a los portugueses Gaspar Enríquez de Granada y Antonio Correa de Amezquita. AHPM, 7780- 290.

75. Nos basamos en lo declarado en carta de poder otorgada por Antonio Mesía y Paz a su hermano el conde de Molina, para continuar este pleito, en Madrid, 13-IX-1657. AHPM, 7652-251. 
mismos desempeñaron las lanas. Pero no cabe duda de que se trató también de una relación cargada de riesgos, que en última instancia afectó muy negativamente a la solvencia financiera de nuestro personaje, pues no podemos pasar por alto el hecho de que al efectuarse el inventario post mortem de su hacienda, en el capítulo de cantidades pendientes de cobro, la partida más abultada estuvo representada por los 725.000 reales que se calculaba que, aproximadamente, le adeudaban el segundo conde de Molina y su hermano Antonio. Y no todo en esta cantidad correspondía a intereses usurarios.

\section{Negociación con lanas del partido mesteño de Cuenca: su Relación con Alonso Muñoz de Castilblanque}

Las comarcas de Cuenca y Molina de Aragón fueron los ámbitos de la Corona de Castilla donde en el transcurso del siglo Xiv se inició el proceso de penetración de los mercaderes italianos en busca de lanas para cubrir la creciente demanda que de esta materia prima se generó en las ciudades pañeras del norte y centro de Italia a partir de los siglos bajomedievales. Se ha llegado a afirmar, haciendo referencia al período final del Medievo, que en aquellos momentos las lanas de Cuenca y Molina eran las más apreciadas por su calidad de cuantas se producían en todo el territorio de la Corona de Castilla ${ }^{76}$. Pero en el transcurso del siglo xvi debió tener lugar un acelerado proceso de mejora de la calidad de las lanas segovianas, y, en menor medida, de las sorianas, puesto que la documentación notarial del siglo XVII no deja lugar a dudas sobre el hecho de que estos dos últimos tipos de lanas, y en muy mayor grado el primero, se cotizaban a unos precios muy superiores a los de las lanas, tanto de Cuenca, como de Molina de Aragón, que eran, junto con las del ducado de Medinaceli, las más baratas entre las procedentes del esquileo de los ganados trashumantes de las comarcas serranas de la Corona de Castilla ${ }^{77}$.

Dada la predilección mostrada por Bartolomé Arnolfo hacia las exportaciones de lanas al mercado italiano, resulta comprensible que se interesase por su adquisición en la región conquense, que ofrecía evidentes ventajas para su transporte hasta los puertos de embarque del Mediterráneo. En su actividad en esta

76. Vid. Iradiel Murugarren, P.: Evolución de la industria textil castellana en los siglos XIII-XVI. Factores de desarrollo, organización y costes de la producción manufacturera en Cuenca. Salamanca, 1974, pp. 169-73.

77. Estas diferencias de precios quedan bien recogidas en la pragmática de tasa de precios de una amplia gama de mercancías aprobada por Felipe IV en 1627, y confirmada con modificaciones en 1628. Vid. VIÑas, C.: «Cuadro económico-social de la España de 1627-28. Pragmáticas sobre tasas de las mercaderías y mantenimientos, jornales y salarios», Anuario de historia económica y social, 1 (1968), pp. 715-772. 
región desempeñó un papel central la relación que estableció con Alonso Muñoz de Castilblanque, el mayor propietario de ganado trashumante de la ciudad de Cuenca en aquellos momentos. Fue este un individuo que, además de reunir una cabaña de enormes dimensiones, se interesó por otros muy diversos negocios, entre los que figuraron los arrendamientos de rentas eclesiásticas. Su inclinación por los negocios especulativos tuvo su traducción en el hecho de que, a diferencia de lo que era habitual entre los señores de ganados de todos los partidos mesteños serranos, asumió regularmente las tareas de lavado y ensacado de las lanas obtenidas del esquileo de sus ganados, a las que a veces sumaba otras partidas compradas a otros ganaderos, para lo cual se hizo con la propiedad de un lavadero en el lugar de Zarzuela. Pero las sacas de lana en limpio procedía luego a venderlas a otros mercaderes exportadores, residentes mayoritariamente en Madrid, entre los cuales hubo algunos italianos, como Jerónimo Bifi y el propio Bartolomé Arnolfo ${ }^{78}$.

A partir de 1646 la relación de negocios de nuestro protagonista con este magnate ganadero conquense se hizo mucho más estrecha y estable debido a que ese año se hizo cargo de la administración de su hacienda, tras ser nombrado para tal efecto por el Consejo de la Inquisición, a raíz de que Alonso Muñoz fuese procesado, acusado del asesinato de un bandolero aragonés llamado Mosén Jacinto $^{79}$. Fue el propio Alonso Muñoz de Castilblanque quien sugirió su nombramiento en un memorial que elevó al Consejo de la Inquisición el 2 de diciembre de 1645. En él manifestaba que, a su juicio, el problema principal al que entonces se enfrentaba la gestión de su hacienda era la falta de capital líquido con el que afrontar los pagos que imperiosamente había que realizar, pues para todo lo demás bastaban los mayorales, convenientemente supervisados por él mismo. Por ello entendía que convenía nombrar como administrador «persona poderosa de esta Corte... en quien entre el dinero que proceda de las ventas de las lanas y carnes, esté seguro, y socorra con puntualidad las necesidades de la hacienda, y pague lo que por Vuestra Alteza se libre». Tal persona solo cabía encontrarla en Madrid, «donde hay hombres caudalosos y que tratan del género de lanas, y no en Cuenca, donde no los hay, sino que cualquier cosa que se haya de vender será a mucho menor precio». Y, por ello, concluyó sugiriendo los nombres de Bartolomé Arnolfo, Jerónimo Bifi, Pedro María Vivaldo, «u otro de su calidad».

78. Contrato de venta por adelantado de 4.000 arrobas de lana del esquileo del año 1645, en Madrid 3-XI-1644, en Archivo Histórico Nacional [en adelante AHN], Inquisición, 1916-10. Una cláusula dispuso que don Alonso beneficiaría las lanas por cuenta del saboyano en su lavadero de Zarzuela, y las remitiría a Alicante a las personas que este último le ordenase, cargándole por ello lo que les había cargado, tanto a él como a Jerónimo Bifi, en años anteriores por las lanas que les había vendido y beneficiado en ese mismo lavadero.

79. El proceso tuvo lugar ante el Consejo de la Inquisición porque Alonso Muñoz de Castilblanque era contador del Santo Oficio de Cuenca. La documentación de este proceso, en la que nos basamos, en AHN, Inquisición, 1916-4. 
El Consejo de la Inquisición atendió su solicitud, y nombró administrador a Bartolomé Arnolfo, que desempeñó el cargo hasta su muerte. De hecho, bastante antes de hacerse formalmente cargo de esta administración ya había efectuado importantes adelantos de dinero a este atribulado ganadero, con evidentes problemas de liquidez. Lo hizo en el año 1640 por un total de 43.000 reales de vellón, que le entregó en diversas partidas ${ }^{80}$. De nuevo en noviembre de 1644 le volvió a prestar 51.000 reales, para que se los devolviese a fin de junio de 1645, a los que luego se sumaron otros 50.000 en abril de 1645, y otras cantidades varias que hubieron de ser reintegradas mediante la entrega de todas las lanas y añinos procedentes del esquileo de sus ganados en junio de $1645^{81}$.

Pero estos adelantos de dinero pasó a realizarlos de forma sistemática en su nueva condición de administrador a partir de 1645, cargando por ellos la acostumbrada tasa de interés del 10\% anual. Para recuperar las cantidades adelantadas ingresó el producto íntegro de las ventas de lanas, añinos y carneros de la cabaña que administraba. Pero llama la atención constatar que, en lugar de quedarse él mismo con las lanas, para comercializarlas por su cuenta y riesgo en Italia, como había hecho en ejercicios anteriores, prefirió por el contrario venderlas a otros grandes mercaderes exportadores, como el judeoconverso portugués Antonio Rodríguez Gómez, que se quedó con las del esquileo de $1647^{82}$, y con las del de 1649 , en este caso junto con las de otros ganaderos conquenses que sumaron un total de 7.000 arrobas $^{83}$.

La producción lanera de la cabaña de Don Alonso Muñoz era cuantiosa, pero la cotización de sus fibras era muy inferior a la que alcanzaban las de mayor reputación entre las denominadas cabañas «segovianas leonesas», como era la de los Mesía de Tovar. Así, mientras que en 1647 al conquense se les pagaron sus lanas a 21 reales de vellón por arroba, Antonio Mesía y Paz, hermano del conde de Molina, vendió las suyas a 66 reales de vellón, es decir, a un precio más de tres veces superior. Por consiguiente los ingresos que Bartolomé Arnolfo obtenía de la venta de lanas y añinos de la que sin duda era la mayor cabaña de Cuenca en

80. Contrato de obligación por 30.000 reales en Madrid, 5-XII-1640 en AHPM, 3702-641v. Otro nuevo contrato por 13.000 reales más en Madrid, 17-XII-1640 en AHPM, 3702-732.

81. AHN, Inquisición, 1916-10.

82. Noticia de la venta de las 5.400 arrobas en sucio del esquileo de 1647 en la liquidación de cuentas entre Bartolomé Arnolfo y Antonio Rodríguez Gómez en Madrid, 13-III-1648, en AHPM, 7590-241.

83. El contrato de venta en AHPM, 7591-461, Madrid, 23-V-1649. Se calcula que de los ganados de Alonso Muñoz serán unas 4.600 arrobas, y las 2.400 restantes procederían de los ganados del licenciado Juan de Ayala, Don Jerónimo Enríquez y otros vecinos y ganaderos de la ciudad de Cuenca. Por la liquidación de cuentas en Madrid, 6-V-1650, parece que de los ganados de Alonso Muñoz de Castilblanque solo se entregaron 3.380 arrobas lana y añinos, que alcanzaron un valor de 79.392 reales. AHPM, 7592-476. 
aquellos momentos no alcanzaban las dimensiones espectaculares a las que le tenían acostumbrado sus tratos con el primer conde de Molina de Herrera y sus dos hijos. Por ello mismo la recuperación de los dineros adelantados a Alonso Muñoz de Castilblanque debía avanzar con desesperante lentitud, y, dado que no cesó de efectuarle préstamos, la cuantía total de la deuda no dejó de incrementarse, de modo que cuando al saboyano le sorprendió la muerte en febrero de 1650 alcanzaba ya la elevada cifra de 157.427 reales de vellón ${ }^{84}$. Alonso Muñoz se obligó entonces a hacer efectivo el pago de este dinero a sus herederos en breves plazos que concluían a mediados de junio de 1652. Pero no hizo honor a su compromiso, puesto que todavía en 1662 continuaba pendiente ante el Consejo de la Inquisición un pleito entre el administrador de la hacienda del difunto Bartolomé Arnolfo y los herederos del también difunto Alonso Muñoz de Castilblanque en torno a la liquidación de la mencionada deuda ${ }^{85}$.

\section{Bartolomé Arnolfo, SeÑor de ganados trashumantes}

Uno de los elementos que más contribuyen a conferir su singularidad al perfil de Bartolomé Arnolfo como hombre de negocios de origen extranjero en el Madrid de mediados del siglo xvi deriva del hecho de que al final de su trayectoria llegó a convertirse en propietario de una grande y reputada cabaña de ganados trashumantes. Dominados todavía por la idea que machaconamente se ha venido repitiendo en las obras de síntesis, según la cual el negocio de la explotación de ganados trashumantes, amparado por la Mesta, fue cosa de nobles y monasterios, imbuidos de una visión del mundo de fuerte impronta «feudal» ${ }^{86}$, nos puede resultar a primera vista sorprendente que un saboyano venido a Madrid en la década de 1620 para ganarse la vida como comerciante y financiero llegase a convertirse en uno de los mayores propietarios de ganado ovino trashumante del reino, dueño de una cabaña que despuntaba entre las productoras de las lanas de mayor reputación y precio de toda la Corona de Castilla.

No obstante, si nos despojamos de los prejuicios más arraigados en nuestra historiografía, y analizamos más de cerca la realidad que nos desvelan las fuentes

84. Esta es la cifra que figura en el ajustamiento de cuentas entre los herederos de Bartolomé Adolfo con la parte de Alonso Muñoz. En el inventario post mortem del propio Bartolomé Arnolfo la cantidad adeudada se estima en 157.776 reales.

85. Noticia en AHPM, 9113-10, Madrid, 30-XII-1662.

86. La bibliografía sobre Mesta y trashumancia se ha incrementado de forma apreciable en las últimas décadas. Un estado de la cuestión en Pérez Romero, E. : «L'historiographie sur la transhumance en Espagne, 1983-2003», en LAFFONT, P. (ed.): Transhumance et estivage en Occident des origines aux enjeux actuels. Presses Universitaires du Mirail, Toulouse, 2006, pp. 97-108. Nuestro punto de vista sobre esta temática en Diago Hernando, M.: Mesta y trashumancia en Castilla. Siglos XIII a XIX. Arco Libros, Madrid, 2002. 
documentales conservadas, advertiremos que este fenómeno, aparentemente extraño e incluso contradictorio, no lo era tanto. Así, en primer lugar, cabe destacar que a partir del momento en que la Corte fijó su sede con carácter definitivo en Madrid en 1606 la figura del señor de ganados trashumantes, prácticamente ausente del panorama social de esta villa durante el período medieval y el siglo $\mathrm{XvI}^{87}$, comenzó a hacerse cada vez más habitual entre sus vecinos. Por supuesto, la mayoría de estos madrileños que poseyeron grandes cabañas de ganado trashumante fueron súbditos castellanos de procedencias muy diversas, aunque, en contra de lo que se ha afirmado a veces, no se trató mayoritariamente de individuos pertenecientes al grupo de la alta nobleza titulada. Por el contrario, un gran número de ellos fueron individuos que prosperaron gracias a su dedicación a los negocios mercantiles y financieros y que solo en una segunda fase lograron su integración en el estamento noble, con o sin título ${ }^{88}$. La dedicación simultánea al comercio y a la explotación de ganado ovino trashumante, preferentemente del de raza segoviana que pastaba en verano en las montañas de León, fueron rasgos que caracterizaron el perfil socioeconómico de cada vez mayor número de personas en Madrid conforme fue avanzando el siglo xvir. Lo que confiere mayor singularidad a Bartolomé Arnolfo es el hecho de que a ello se unió la circunstancia de que se trataba de un individuo de origen extranjero. Pero tampoco desde este punto de vista su caso puede considerarse absolutamente excepcional, pues se conocen otros ejemplos notorios de mercaderes extranjeros, sobre todo italianos, que se sintieron atraídos por esta actividad económica tan peculiarmente castellana, y que no podemos detenernos aquí a enumerar.

Por su condición de mercader exportador de lanas finas, Bartolomé Arnolfo estuvo en estrecho contacto con el mundo de la ganadería trashumante desde que se asentó en Madrid. Pero fue en la etapa final de su vida cuando decidió dar el gran salto para convertirse él mismo en propietario de una gran cabaña, que pasó a gestionar personalmente, con la imprescindible colaboración de expertos mayorales reclutados en comarcas con larga tradición ganadera. La ocasión se la proporcionó, como ya hemos visto, el agravamiento de las dificultades financieras de la familia Mesía de Tovar a mediados del siglo xvir, que forzó en el verano del año 1644 al segundo conde de Molina y a su hermano Antonio a desprenderse de una parte importante de sus cabañas, para venderlas a nuestro personaje a fin de amortizar parte de la abultada deuda que tenían con él contraída. Las

87. Vid. Guerrero Mayllo, A.: Familia y vida cotidiana de una élite de poder. Los regidores madrileños en tiempos de Felipe II. Siglo XXI, Madrid, pp. 247-8.

88. Vid. HernÁNDEZ BeNíteZ, M.: «Señores trashumantes entre Madrid y Segovia: Los Negrete», en Extremadura y la trashumancia (siglos XVI-XX). Editora Regional de Extremadura, Mérida, 1999, pp. 55-66. Y A la sombra de la Corona. Poder local y oligarquía urbana (Madrid, 1606-1808). Siglo Veintiuno Editores, Madrid, 1995, capítulo 6. 
escrituras de venta de los rebaños, con sus posesiones de dehesas de invernadero y puertos de agostadero en la montaña de León, se otorgaron en Santo Domingo de las Posadas el 23 de octubre de 1644. Por virtud de las mismas, el segundo conde de Molina traspasó ganados a Bartolomé Arnolfo por valor de 125.674 reales, mientras que los que le vendió su hermano Antonio Mesía y Paz alcanzaron un valor muy superior, en concreto 214.314 reales ${ }^{89}$. Sin entrar aquí a analizar los detalles de la operación, interesa destacar que por virtud de la misma Bartolomé Arnolfo se vio convertido, de la noche a la mañana, en un gran señor de ganados trashumantes, propietario de más de 13.000 cabezas productoras de la lana de la máxima calidad, que podía rivalizar con la de la cabaña del monasterio del Paular, tradicionalmente considerada como la de mayor reputación del reino.

No tenemos noticia de que después de esta gran operación realizase otras adquisiciones de envergadura. Pero algunos indicios sugieren que persiguió de forma deliberada y sistemática el objetivo de incrementar en le medida de lo posible el tamaño de su cabaña. Entre ellos podemos destacar las operaciones de compra de corderos machos que realizó en el año 1646 a varios ganaderos de la comarca de Piedrahita y El Barco de Ávila, en virtud de las cuales se hizo con la propiedad de 850 cabezas de la cría de ese año ${ }^{90}$.

Las informaciones reunidas no permiten reconstruir en detalle la evolución del tamaño de la cabaña de Bartolomé Arnolfo desde su constitución en el año 1644. Pero nos ha sorprendido constatar que, al tomar a renta en 1645 la finca de Tabladillo en la Tierra de Ávila para esquilar allí sus ganados, llegó a un acuerdo con el deán y cabildo de la catedral abulense para entregarles durante cuatro años una cantidad fija por razón del diezmo de las lanas, que se fijó en 1.458 reales de vellón, en consideración al hecho de que se estimaba que se esquilarían cada año en dicha finca unas 17.000 cabezas de ganado ${ }^{91}$. Las cabezas adquiridas de los Mesía de Tovar el año anterior debieron ser, no obstante, muchas menos, por lo que no alcanzamos a explicar de dónde podían proceder el resto de ganados. Es probable que se tratase de una estimación calculada muy al alza, y mezclando ovejas y corderos. Más cercana a la realidad debía estar la cifra que proporciona el inventario de bienes realizado tras la muerte del saboyano en febrero de 1650, donde se indica que su cabaña, que se encontraba pastando entonces en Extremadura, sumaba alrededor de 14.500 cabezas, sin contar los corderos de la cría

89. Ajuste de cuentas del conde con Bartolomé Arnolfo, en Madrid, 16-XI-1644. AHPM, 77811265. Y ajuste con Antonio Mesía y Paz, en Madrid, 17-XI-1644 en AHPM, 7781-1269.

90. AHPM, 7783-241, Madrid, 1-V-1646.

91. AHPM, 7782-284, Madrid, 6-III-1645. Cuando se renovó el acuerdo por otros cinco años, pero aunque se elevó la cuantía que se había de abonar a 2.040 reales de vellón anuales, de nuevo se hizo constar que esta cifra se había calculado en función de la estimación de que se esquilarían cada año 17.000 cabezas. AHPM, 7515-227, Madrid, 16-IV-1648. 
de ese año y otras 1.500 cabezas que el difunto había donado en marzo de 1648 a su hijo Francisco Arnolfo ${ }^{92}$. En cualquier caso no cabe duda de que, aunque los ganados adquiridos a los Mesía de Tovar proporcionaron el núcleo de la cabaña, esta fue incrementando su tamaño porque Bartolomé Arnolfo lo buscó de forma deliberada, lo cual demuestra que su inversión en la actividad ganadera trashumante, aunque sobrevenida, no por ello fue descuidada como algo secundario en la etapa final de su vida, sino todo lo contrario.

Para proporcionar alimento a sus ganados pudo disponer de las mismas dehesas y puertos de montaña en los que habían pastado cuando pertenecían a los Mesía de Tovar, pues los rebaños le fueron cedidos con sus correspondientes derechos de posesión. Como rasgo novedoso en su forma de negociar con los propietarios de los pastos cabe hacer constar que, en contra de la práctica habitual entre los señores de ganados trashumantes, él efectuó con frecuencia adelantos de dinero a dichos propietarios, anticipándoles voluntariamente el pago de las rentas ${ }^{93}$.

La cabaña, pese a lo tardío de su adquisición, terminó siendo apreciada por Bartolomé Arnolfo y su familia como un elemento fundamental de su patrimonio, que había que tratar a toda costa de conservar. Lo reconocieron explícitamente a raíz de su muerte su viuda e hijos, quienes declararon que la «hacienda más principal» que había dejado el difunto consistía en el dicho ganado. Y que no se trataba de meras palabras lo demuestra la constatación del hecho de que sus dos hijos varones hicieron un extraordinario esfuerzo por mantener en su propiedad al menos una parte de la misma, en circunstancias extremadamente difíciles, habida cuenta que cuando murió su padre dejó una hacienda tan cargada de deudas que ellos prefirieron renunciar a la herencia.

En efecto, para atender las demandas de los acreedores que se presentaron al concurso abierto tras la muerte de Bartolomé Arnolfo, la cabaña fue puesta a la venta por la autoridad judicial en pública subasta y rematada en el financiero madrileño Juan Bautista de Benavente, que la adquirió en compañía con Francisco de Ciudad Rodrigo. Varios años después, sin embargo, Diego Arnolfo llegó a un

92. El inventario post mortem en AHPM, 3390-550. En este año de 1650 se obtuvieron 3.500 arrobas de lanas y añinos del esquileo de la cabaña, según consta por el contrato de venta.

93. En 1645 prestó 3.000 reales a Pedro Barrantes de Aragón, regidor perpetuo de Alcántara, a cambio de que accediese a prorrogarle el arrendamiento de la dehesa de Torre de Sanabria por otros tres años. AHPM, 7782-600, Madrid, 6-V-1645. En septiembre de 1648, el marqués de Camarena recibió anticipados 3.300 reales de vellón a cuenta de la renta de la dehesa de Torrejón del Hondonero, en término de Cáceres, que debía pagar para fin de abril de 1649. AHPM, 7590-931, Madrid, 2-IX1648. Al conde del Puerto, Diego de Carvajal y Vargas, le adelantó en varias ocasiones el pago de las rentas que le debía por sus dehesas. En Madrid, 30-XII-1647, abonó los 24.000 reales que debía pagar a fin de marzo de 1648 por la renta de las dehesas de Los Pizarrales, en término de Trujillo. AHPM, 7589-638. En 23-X-1648 adelantó el pago de 21.120 reales de vellón que, según contrato, debía hacer efectivo a fin de marzo de 1649. AHPM, 7590-1100. 
acuerdo con el primero, formalizado en Madrid el 20 de enero de 1655, por virtud del cual este accedió a venderle la mitad de las 14.141 cabezas de ganado ovino que él había adquirido por bienes de Bartolomé Arnolfo, y que hasta entonces había estado explotando en compañía con Francisco de Ciudad Rodrigo. A cambio Diego Arnolfo renunció al derecho de usufructo que le pertenecía a un cuarto de las casas principales que su padre había edificado en la calle Carretas, las cuales había adquirido también Juan Bautista de Benavente en el concurso de acreedores ${ }^{94}$.

El hermano de Diego, Francisco Arnolfo, no quiso, por su parte, quedarse tampoco sin participación en los ganados que había dejado su padre. Podía apelar para ello a la donación que este le había efectuado antes de morir, en marzo de 1648, de 1.500 cabezas de ganado ovino. Y, en efecto, pocas semanas después del fallecimiento de Bartolomé Arnolfo otorgó poder a Cristóbal Martínez de Ontalora para que tomase posesión de dichas cabezas, repartidas en tres rebaños ${ }^{95}$. Pero no sabemos si efectivamente consiguió que las mismas quedasen excluidas del secuestro impuesto por los jueces sobre el conjunto de la cabaña, hasta que hubiesen sido satisfechas las demandas de los acreedores del difunto. Lo que sí podemos afirmar es que Francisco Arnolfo pudo también convertirse en señor de ganados trashumantes, si no lo era antes, gracias a un acuerdo al que llegó con su hermano Diego el 24 de noviembre de 1655 , pocos meses después de que este último hubiese cerrado con Juan Bautista de Benavente la operación de compra de la mitad de la cabaña paterna. En virtud de dicho acuerdo Diego le traspasó la propiedad de la mitad de los ganados que había adquirido por virtud de dicha compra, que se calculó que ascendería a 3.600 cabezas, pagándoselas a razón de 27 reales cada una ${ }^{96}$.

Este empeño de los hermanos Diego y Francisco Arnolfo por seguir adelante con el negocio ganadero trashumante resulta digno de resaltar, puesto que muchos de los mercaderes que en Castilla invirtieron en la compra de rebaños de ovino trashumantes, tanto en el siglo XVI como en el XVII, mantuvieron sus explotaciones durante períodos relativamente breves de tiempo ${ }^{97}$. La circunstancia de que se trataba de miembros de una familia de origen extranjero hace que todavía resulte más sorprendente este interés por una actividad que se suponía propia de familias muy arraigadas en la sociedad castellana. Pero no hemos de olvidar que la de los Arnolfo fue una familia que persiguió con tenacidad el objetivo de echar profundas raíces en su patria de adopción. Desde este punto de vista su trayectoria ofrece evidentes paralelismos con la familia de origen genovés de los

94. AHPM, 7597-54, Madrid, 20-I-1655.

95. AHPM, 7517-256, Madrid, 2-IV-1650.

96. AHPM, 7595-1123, Madrid, 24-XI-1655.

97. Algunos ejemplos tomados del ámbito soriano en Diago Hernando, M.: «Mercaderes propietarios de ganado trashumante en la cuadrilla mesteña soriana en los siglos XVI y XVII», Studia Historica. Historia Moderna, 26 (2004), pp. 255-282. 
Sanguineto, que también apostó fuerte por la explotación a gran escala de ganado ovino trashumante, a la que sus miembros estuvieron dedicados a lo largo de varias generaciones. Y por ello ambas familias nos proporcionan paradigmáticos ejemplos que sirven para poner en cuestión la validez de la tesis, machaconamente repetida en las obras de síntesis de mayor circulación, que caracteriza a la Mesta como un universo dominado por monjes y nobles, que acaparaban la mayor parte de la cabaña ovina trashumante del reino.

\section{EL NEGOCIO FINANCIERO}

Habiendo servido a Juan Lucas Palavesín como oficial mayor de sus libros, nada tiene de extraño que Bartolomé Arnolfo dedicase una parte importante de su actividad a los tratos financieros, en todas sus vertientes. Al dar cuenta de sus negocios con los Mesía de Tovar y con Alonso Muñoz de Castilblanque hemos tenido ocasión de conocer su faceta como prestamista de dinero destinado a cubrir las necesidades de liquidez de las grandes explotaciones ganaderas trashumantes. Ahora solo nos cabe añadir que, aunque con ningún otro señor de ganados trashumantes mantuvo una relación tan prolongada como con los mencionados, que implicase la movilización de tan enormes sumas de dinero, también efectuó numerosos préstamos de menor cuantía a otros muchos señores de ganados trashumantes de las comarcas de Segovia y Ávila, con los que también tuvo tratos de compra de lanas. Entre ellos nos encontramos a vecinos de El Espinar y Villacastín, como Bartolomé Márquez de Prado y su cuñado Pedro Juan de Pedraza ${ }^{98}$, y vecinos de la sierra abulense como Juan de Solís, vecino de El Barco de Ávila, recaudador de las rentas del duque de $\mathrm{Alba}^{99}$.

Individuos pertenecientes a otros muy diversos grupos sociales también recibieron de él préstamos de dinero con el que atender muy variadas necesidades. Entre ellos encontramos miembros de la alta nobleza castellana residentes en la Corte, que vivían en una situación de falta crónica de liquidez que les forzaba a recurrir de forma sistemática al crédito. Así, nuestro personaje concertó varios asientos con el marqués de Malagón y conde de Villalonso, adelantándole importantes cantidades de dinero para que pudiese pagar a sus censualistas ${ }^{100}$.

98. Un préstamo de 3.000 reales en AHPM, 7782-35, Madrid, 10-I-1645. Otro de la misma cantidad en AHPM, 7590-1009, Madrid, 30-IX-1648. Y otro de 5.000 reales en AHPM, 7590-1104, Madrid, 24-X-1648. En todos los casos eran préstamos a corto plazo, para devolver en el mes de mayo.

99. AHPM, 3703-742, Madrid, 29-VI-1641. Recibió prestados 11.237 reales, que se obligó a devolver para mediados de agosto.

100. En 1642 acordó adelantarle 6.000 ducados destinados en su integridad a pagar réditos de censos, a cambio de que el marqués le consignase 2.526 .883 mrs. sobre sus rentas del estado de Malagón de 
Otros miembros de la nobleza recibieron préstamos con carácter más puntual, con condición de devolver el dinero en muy breve plazo de tiempo. Así, en 1645 prestó al conde de Gramal 4.000 reales, mitad en plata doble y mitad en vellón ${ }^{101}$, y en mayo de 1644 el señor de Caracena, Mateo Antonio de Sandoval Pacheco, recibió 1.650 reales de vellón, que se obligó a devolver en el plazo de seis meses, entregando en prenda una tapicería con la historia de Jacob ${ }^{102}$. Pero entre sus clientes también hubo individuos de condición social mucho más humilde, que recibieron adelantadas cuantías bastante más modestas. Es el caso, por ejemplo, de Lorenzo Rodríguez, vecino de Paracuellos del Jarama, que fue muchos años su proveedor de paja y cebada para los caballos ${ }^{103}$. Por su parte, en enero de 1644 Benito Pi, administrador de la encomienda de Mérida, recibió prestados en Madrid 400 reales de vellón, que se obligó a devolver en Mérida en el plazo de dos meses, haciendo entrega allí del dinero al mayoral del conde de Molina ${ }^{104}$. Y en marzo de 1649 Diego Martínez Márquez, procurador del concejo cacereño de Botija que entonces estaba desplazado en Madrid, recibió allí otros 400 reales con la condición de devolverlos descontándolos del precio que Bartolomé Arnolfo había de pagar por el arrendamiento de la dehesa boyal de este concejo en el plazo de pago fijado para el 15 de marzo ${ }^{105}$.

Por fin, también proporcionó crédito a destacados mercaderes y hombres de negocios madrileños que recurrieron a él como persona bien conectada con las principales plazas mercantiles de la Península. Así, en 1641 uno de los obligados del pescado de Madrid, Mateo de Orcasitas, le solicitó que contactase con su correspondiente en el puerto de Cartagena, Juan Lorenzo Rato, a fin de que le facilitase dinero en dicha plaza con el que poder comprar pescado en el viaje que iba a emprender a la misma. Gracias a ello Mateo de Orcasitas pudo disponer de 40.000 reales, que se obligó a hacer efectivos al saboyano en Madrid tras su regreso ${ }^{106}$.

Otra importante faceta de su actividad financiera es la de los adelantos de dinero efectuados a la Monarquía. Ciertamente no formó parte del grupo de los

ese mismo año. Liquidación de cuentas de la operación en AHPM, 7781-1338, Madrid, 7-XII-1644. En 1644, por virtud de un nuevo contrato, firmado en Toro, 8-VI-1644, se obligó a anticiparle en los siguientes cuatro años 10.625 ducados anuales, que le haría efectivos cada año en dos pagas, en San Juan y Navidad, para que con este dinero se pagasen los réditos de los censos impuestos con facultad real sobre sus estados. Noticia en AHPM, PN, 7782-1094, Madrid, 25-X-1645.

101. AHPM, 7782-305, Madrid, 10-III-1645.

102. AHPM, 7780-685, Madrid, 20-V-1644.

103. Un ejemplo en AHPM, 7780-172, Madrid, 18-II-1644. Préstamo de 700 reales para devolver a fines del siguiente mes de junio.

104. AHPM, 7780-37, Madrid, 14-I-1644.

105. AHPM, 7591-198, Madrid, 5-III-1649.

106. AHPM, 3703-373, Madrid, 27-III-1641. Obligación de Mateo de Orcasitas y Blas García de Bustamante, mercaderes de hierro, obligados del pescado de Madrid. 
asentistas más célebres por la frecuencia y envergadura de sus tratos con la Real Hacienda durante el reinado de Felipe $\mathrm{IV}^{107}$. No obstante no podemos olvidar que durante la primera fase de su trayectoria en Madrid mantuvo una estrecha relación con uno de los principales asentistas de aquellos momentos, el genovés Juan Lucas Palavesín. Y, además, tenemos constancia de que él mismo concertó por su propia cuenta algunos asientos, concentrados en los primeros años de la década de 1640. En concreto sabemos de un asiento por el que se obligó a poner 50.000 ducados en la Corte en moneda de plata hacia $1640^{108}$. Y poco después, en 1642 , concertó otro por virtud del que se obligó a anticipar a la Real Hacienda 24.000 ducados a lo largo de dicho año, a razón de 2.000 por mes, a cambio de la cesión del derecho a cobrar 32.000 ducados que esta debía recaudar en Soria y su provincia ${ }^{109}$.

Junto a la concesión de préstamos a particulares y a la Real Hacienda, otra faceta fundamental de su actividad financiera fue la negociación de letras. Es mucha la información que al respecto proporcionan los protocolos notariales, y no disponemos aquí de espacio para analizarla en detalle. Nos limitaremos, por consiguiente, a indicar que mantenía estrechos vínculos de negocios con destacados financieros italianos, en su mayoría genoveses. Cobró en Madrid numerosas letras otorgadas en plazas italianas, no solo del norte, como Plasencia o Nove, sino también del sur, como Palermo. Y también disponía de abundante crédito en dichas plazas. Lo demuestra, por ejemplo, una operación que realizó en 1641 ordenando por letra a Juan Benito Espínola, de Génova, que pagase en la próxima feria de la Aparición de Plasencia 3.085 escudos a un convento genovés, en el que era monja la hermana y heredera universal del mercader genovés Joseph Boaci, recientemente fallecido en Madrid. De esta manera Bartolomé Arnolfo pudo hacer efectivos a dicha monja los 1.588.949 mrs. de plata doble que le adeudaba por virtud del ajustamiento de cuentas de la administración que había tenido de la hacienda de este mercader tras su muerte ${ }^{110}$.

La información relativa a negociación de letras por Bartolomé Arnolfo también pone en evidencia sus estrechos vínculos con hombres de negocios genoveses residentes en otras plazas de la Península Ibérica, entre los cuales destaca Antonio Taliacarne,

107. Buena prueba es que no hemos encontrado mencionado su nombre en el trabajo clásico de Domínguez OrTIZ, A., op. cit.

108. Noticia en AHPM, 3702-580.

109. Detalles sobre este asiento en AHPM, 3703-298. Los 8.000 ducados de diferencia entre los 24.000 que debía adelantar a la Real Hacienda, y los 32.000 que se le consignaban en rentas del partido de Soria, quedaban a su favor, en concepto de intereses y compensación por costes del transporte de moneda y otros gastos derivados de la recaudación.

110. AHPM, 3703-39, Madrid, 9-I-1641. 
residente en Granada, con el que compartió el interés por la exportación de lanas. Y, por fin, otra plaza financiera de primera fila donde residieron genoveses con los que estuvo en constante contacto fue Amberes, donde en 1649 residía Carlos Palavesin ${ }^{111}$.

\section{Balance de la actividad de Bartolomé Arnolfo y su legado: el Concurso DE ACREEDORES}

De todas las informaciones hasta ahora proporcionadas se deduce que Bartolomé Arnolfo desarrolló una actividad extraordinariamente diversificada, que contempló incluso las inversiones en explotación de minas ${ }^{112}$. Y pese a que, según todos los indicios, residió de forma permanente en Madrid, tuvo intereses en los más diversos rincones de la Europa Occidental e incluso en América, aunque el ámbito que más acaparó su atención, con diferencia, fue Italia. Sus cifras de negocio fueron abultadas, aunque no alcanzasen las dimensiones de las habituales entre los grandes asentistas genoveses o portugueses. Pero lo que no sabemos con tanta seguridad es hasta qué punto la actividad que desarrolló fue rentable. Para responder a esto sería preciso conocer en primer lugar cuál fue el punto de partida, es decir, si por su origen familiar dispuso de suficiente capital propio para poner en marcha con holgura sus negocios. No parece probable, pero nuestra información al respecto es insuficiente y no permite realizar una estimación, siquiera aproximada, sobre los beneficios que le fue proporcionando su actividad a lo largo de su carrera.

A lo largo del presente trabajo hemos hecho abundantes referencias a las grandes cantidades de dinero, distribuidas en partidas de muy diversa magnitud, que Bartolomé Arnolfo puso a disposición de otras personas durante sus años de estancia en Madrid. Pero no hemos podido profundizar tanto en determinar cuál era el origen del dinero que manejaba. Por supuesto hemos encontrado noticias sobre préstamos que le efectuaron personas particulares, con frecuencia de perfil muy mal definido ${ }^{113}$. Y también sabemos que otras personas le entregaron elevadas

111. Cobros por Bartolomé Arnolfo de letras otorgadas en Amberes por Carlos Palavesín en AHPM, 7591-959 y 1049, Madrid, 9-X-1649.

112. En 1643 se concertó con el doctor Francisco Moreno, presbítero, residente en Corte, para la explotación en compañía de una mina de alcohol en el lugar de Sorbeda, en el concejo de Riba de Sil de Yuso, que había sido adjudicada a Bartolomé Arnolfo por la Real Junta de Minas. AHPM, 7779-658 Madrid, 23-VIII-1643.

113. En Madrid, 18-XI-1649, el doctor Enríquez, médico residente en Corte, le prestó 10.600 reales de plata para devolver en plazo de seis meses. En Madrid, 19-IV-1646, Gaspar de Salazar, vecino de Madrid, le prestó 4.400 ducados vellón, para devolver en plazo de un año. En Madrid, 5-II-1650, Don Agustín de Villavicencio, del Consejo de la Inquisición, le prestó 68.640 reales, para devolver en 6-VIII-1650. Copia de los contratos de obligación en AHN, Inquisición, 1916-14. 
cuantías de dinero para que las tuviese en depósito y a su plena disposición cuando se las requiriesen, a las que no hay que descartar que él diese empleo por cuenta propia ${ }^{114}$. Pero se trata de informaciones muy fragmentarias.

Lo que sí sabemos con seguridad es que en el momento de su muerte, en febrero de 1650, quedó adeudando importantes cantidades de dinero a un grupo de acreedores cuya identidad solo conocemos de forma parcial ${ }^{115}$. Como consecuencia se inició un procedimiento judicial de concurso de acreedores, que forzó a sus hijos a renunciar a la herencia, quedando toda su hacienda en manos de un administrador, Alonso Morchón Cavañas, que la gestionó durante muchos años. Solo un análisis en profundidad de la documentación generada en la tramitación de este proceso podría darnos una idea precisa sobre el balance final de los negocios de Bartolomé Arnolfo. Fue un proceso complejo, y que se dilató de forma extraordinaria en el tiempo, pues todavía seguía sin resolver trece años después de su muerte ${ }^{116}$. Pero queda pendiente de localización la mayor parte de dicha documentación.

Probablemente la principal víctima de la apertura del concurso fue la viuda de Bartolomé Arnolfo, que le sobrevivió 9 años, que no bastaron, sin embargo, para que pudiese verlo concluido. Como consecuencia parece que tuvo que vivir en una situación económica bastante precaria. Al menos así cabe deducirlo de la declaración que incluyó en su testamento del año 1659, manifestando que se encontraba «muy alcanzada y necesitada», hasta el punto de que prácticamente vivía a costa y expensas de sus dos hijos, Don Francisco y Doña Ana, para entonces ya también viuda ${ }^{117}$.

Pero, aun si tomásemos al pie de la letra esta declaración, no debe llevarnos a una precipitada conclusión, pues, por otro lado, no podemos pasar por alto el hecho de que los tres hijos de Bartolomé Arnolfo, pese a no haber podido aprovecharse en nada de la herencia dejada por su padre, lograron mantener una posición bastante acomodada en la sociedad madrileña, e incluso fueron capaces de rescatar una parte importante de la cabaña de ganado trashumante que había reunido su padre. No todos los esfuerzos del saboyano durante sus años de

114. En abril de 1649 Bartolomé Arnolfo declaró que tenía en depósito un total de 133.000 reales de plata, que el regidor salmantino Antonio de Vargas Carvajal le había entregado en dos partidas, para que los tuviese en confianza y se los devolviese cuando se lo ordenase. AHPM, 7591-293, Madrid, $1-\mathrm{IV}-1649$.

115. Nos consta que en 1652 Pedro de Verastegui, escribano del rey, Íñigo de Fuentes y Pedro de Salazar Isla, residentes en Corte, habían sido nombrados diputados por los demás acreedores de Bartolomé Arnolfo para administrar sus bienes. AHPM, 7594-726, Madrid, 12-VIII-1652.

116. Vid. AHPM, 9113-5, Madrid, 18-VIII-1663. Poder de Alonso Morchón Cavañas, administrador de la hacienda, para vender algunas propiedades en Villacastín.

117. Poder para testar otorgado por doña Francisca Álvarez de la Torre, viuda de Bartolomé Arnolfo, en AHPM, 6527-37, Madrid, 23-I-1659. 
estancia en Madrid, entregado de lleno a los negocios mercantiles y financieros del más alto nivel, habían sido por tanto en vano, pues había conseguido al menos dejar a sus hijos convenientemente situados. Pero, hecha esta salvedad, no puede dejar de reconocerse que los negocios financieros en la España de Felipe IV eran extraordinariamente arriesgados, y una parte importante de la responsabilidad de que así fuese recayó en la propia Monarquía, que con su desbocada presión fiscal y errática política monetaria creó enormes obstáculos para la buena marcha de los negocios. No hemos podido determinar en qué medida Bartolomé Arnolfo se vio afectado por la suspensión de pagos decretada por este monarca en 1647, que tan desastrosos efectos tuvo para muchos asentistas ${ }^{118}$. Se trata de una pista que habría que seguir al profundizar en el análisis del concurso de acreedores que se abrió a su muerte, aunque, a juzgar por lo que hasta ahora nos consta, nuestro personaje no comprometió grandes sumas en asientos. En su caso, según los indicios disponibles, fue la morosidad de personas particulares, en especial la de los hermanos Mesía de Tovar, la que, a la postre, más perjuicio económico le causó.

\section{Conclusión}

La utilización de una base documental restringida y poco compacta, como son los protocolos notariales madrileños, nos impide dar respuesta concluyente a muchos de los interrogantes planteados a lo largo del presente trabajo. Pese a ello consideramos que la información reunida resulta suficiente para cubrir el objetivo principal que nos habíamos marcado, el de poner de manifiesto algunas interesantes facetas de la actividad desarrollada por un mercader de origen extranjero en Madrid, capital de la Monarquía, a mediados del siglo xvir. Con ello hemos querido contribuir a mejorar nuestros conocimientos sobre la composición y características de la comunidad de extranjeros que progresivamente se fueron haciendo con el control de las finanzas y el comercio exterior de la Corona de Castilla durante los reinados de los Austrias menores. Y al mismo tiempo hemos pretendido profundizar en el estudio del funcionamiento de las grandes empresas de negocios en este período de la historia castellana, poniendo de manifiesto los mecanismos que propiciaron un inextricable entrelazamiento de las actividades mercantiles y financieras, e incluso de otras del sector primario como la cría de ganados, en una común estrategia. Desde este punto de vista la trayectoria de Bartolomé Arnolfo proporciona un ejemplo ilustrativo de indudable interés, sobre todo porque demuestra desde una nueva perspectiva la importante vertiente financiera que tuvo el comercio de exportación de lanas finas en la Castilla del

118. Uno de ellos fue, por ejemplo, el inglés Benjamín Ruit. Vid. Diago Hernando, M.: «Mercaderes y financieros ingleses...» 
siglo xvII. Hasta ahora quienes más han resaltado la conexión existente entre finanzas y exportación lanera en esta centuria lo han hecho llamando la atención sobre el protagonismo alcanzado por los grandes asentistas como exportadores de lanas, que se ha explicado como consecuencia de la necesidad que tenían de disponer de plata en el exterior, para realizar allí las provisiones concertadas con la Real Hacienda ${ }^{119}$. La reconstrucción de los negocios de Bartolomé Arnolfo nos pone de manifiesto otra estrategia, que también habría de ser tenida en cuenta en el futuro a la hora de perfeccionar los modelos explicativos.

119. García SAnZ, A.: «Crédito, comercio y exportación de lana merina» en Bernal, A. M. (ed.): Dinero, moneda y crédito en la monarquía hispánica. Marcial Pons-Fundación ICO, Madrid, 2000, pp. 495-510. Llopis AgElÁN, E.: «La pila de lana de la cabaña trashumante del monasterio de Guadalupe: dimensión, venta y estrategia comercial» en GONZÁLEZ ENCISO A. (ed.): El negocio de la lana en España (1650-1830). Eunsa, Pamplona, 2001, pp. 48 et passim. Y SANZ AYÁN, C.: «Las redes financieras franco-holandesas y la lana en el tránsito del siglo XVII al XVIII», Ibidem, pp. 82 et passim. 